\title{
Optimization of the thermal environment of a small-scale data center in China
}

\section{Article}

Accepted Version

Creative Commons: Attribution-Noncommercial-No Derivative Works 4.0

Meng, X., Zhou, J., Zhang, X., Luo, Z., Gong, H. and Gan, T. (2020) Optimization of the thermal environment of a smallscale data center in China. Energy, 196. 117080. ISSN 03605442 doi: https://doi.org/10.1016/j.energy.2020.117080 Available at https://centaur.reading.ac.uk/88862/

It is advisable to refer to the publisher's version if you intend to cite from the work. See Guidance on citing.

To link to this article DOI: http://dx.doi.org/10.1016/j.energy.2020.117080

Publisher: Elsevier

All outputs in CentAUR are protected by Intellectual Property Rights law, including copyright law. Copyright and IPR is retained by the creators or other copyright holders. Terms and conditions for use of this material are defined in the End User Agreement.

\section{www.reading.ac.uk/centaur}

\section{CentAUR}

Central Archive at the University of Reading

Reading's research outputs online 
Small-Scale Data Center in China

\author{
Xiongzhuang Meng ${ }^{\mathrm{a}}$, Junli Zhou ${ }^{\mathrm{a},}$, Xuejiao Zhang ${ }^{\mathrm{a}}$, Zhiwen Luo ${ }^{\mathrm{b}}$, Hui Gong ${ }^{\mathrm{a}}$, Ting \\ $\mathrm{Gan}^{\mathrm{a}}$ \\ ${ }^{a}$ School of Civil Engineering and Architecture, Wuhan University of Technology, \\ Wuhan, China \\ ${ }^{b}$ School of the Built Environment, University of Reading, Reading, UK
}

\begin{abstract}
In data centers, a large number of IT sever racks with different heat dissipation rates are arranged in multiple rows, leading to much higher per-unit heat release and therefore more uneven temperature distribution than in general buildings. This paper chooses a small-scale data center located in China to analyze the thermal environment for the operation of these critical equipments. The wind speed and temperature in the data center were measured, and a corresponding computer room model was established via computational fluid dynamics (CFD) simulation software. Based on it, the characteristics of flow field and temperature field of the data center were analyzed. The optimization methods for problem of uneven temperature distribution and chaotic air supply in the data center were proposed and verified by evaluation index. Furthermore, the return temperature index(RHI) increased from 0.918 to 0.93 , the return heat index(RTI) reduced from 0.222 to 0.342 .
\end{abstract}

Keywords: Data center; Thermal environment; On-site measurement; CFD simulation

\title{
1. Introduction
}

Data center refers to a place that provides the operating environment for centralized electronic information equipment [1]. It can be either one or more buildings or part of a building, and typically includes a computer room, auxiliary area, support area, and administrative area. The computer room that mostly researchers focus on mainly consists of IT servers, air conditioning system, lighting system, and monitoring system. The air conditioning system will provide a good thermal environment for the safe and efficient operation of IT servers. Autonomic computing center is applied as artificial intelligence changes the way people live and work, but it is limited by its technology and practices. Small-scale and medium-scale data centers are widely used in various fields as the basic guarantee of modern science and technology such as in intelligent manufacturing, cloud computing, and big data [2-3]. However, in contrast to general buildings, the heat release of a data center is higher, and the stable operation of the IT servers has more strict requirements with regard to air temperature and humidity. Table 1 summarizes the thermal environmental design requirements in data center [4].

\footnotetext{
*Corresponding author.

E-mail address: jlzhou@whut.edu.cn (J. Zhou)
} 
Table.1. IT equipment thermal environmental specifications

\begin{tabular}{|c|c|c|c|c|c|}
\hline \multirow{2}{*}{ Class } & \multicolumn{2}{|c|}{ Allowable } & \multicolumn{2}{|c|}{ Recommended } & \multirow{2}{*}{$\begin{array}{c}\text { Dew-poin } \\
\left({ }^{\circ} \mathrm{C}\right)\end{array}$} \\
\hline & $\mathrm{DB}\left({ }^{\circ} \mathrm{C}\right)$ & $\mathrm{RH}(\%)$ & $\mathrm{DB}\left({ }^{\circ} \mathrm{C}\right)$ & $\mathrm{RH}(\%)$ & \\
\hline 1 & $15-32$ & $20-80$ & $20-25$ & $40-55$ & 17 \\
\hline 2 & $15-35$ & $20-80$ & $20-25$ & $40-55$ & 21 \\
\hline 3 & $5-35$ & $8-80$ & N/A & N/A & 28 \\
\hline 4 & $5-40$ & $8-80$ & N/A & N/A & 28 \\
\hline NEBS & $5-40$ & $5-85$ & $18-27$ & Max55 & 28 \\
\hline
\end{tabular}

*DB, RH and NEBS represents the dry ball temperature, relative humidity and network equipment-building system respectively.

Due to the increasing demand for data centers in recent years, IT servers in the computer room tend to be smaller in size, diversified in function, and high-speed in operation, which further leads to an increased heat dissipation per unit area [5]. Different racks and different servers in the same rack may differ in their heat dissipation. Under the same air conditioning system, some high-heat emission servers cannot fully dissipate heat, thus forming local hot spots in the computer room [6]. When the local temperature exceeds the limit, the server will shut down and pose a severe threat to the security of the data center.

\subsection{Previous works on the thermal environment of data centers}

The problem of energy consumption in data center computer room is very prominent. Recent research has proposed some technologies to mitigate the high energy consumption of data centers, such as free cooling, thermosyphon, airflow management, and cooling management [7]. For example, it is found that the air-side economizer had superior energy saving potential, but the water-side economizer provided a short payback period [8]. Zhang et al. stated that a hybrid cooling system with water-side economizer provided reliability and availability for design and operation of data centers [9]. Shao et al. indicated an integrated system of mechanical refrigeration and thermosyphon, which could use natural cold source effectively [10].

Although many cooling methods have been applied, in some cities, conventional air conditioners are still be intensively used in data centers. Therefore, a suitable thermal environment is the basic guarantee for the normal operation of most IT servers in the computer room [7]. Generally, designers adopt the practice of increasing the ventilation rate and reducing the supply air temperature to resolve the local hot spots issues in the data center, so that the energy consumption of the refrigerating unit is consequently further increased. When it doesn't work, managers can only place ice in the overheated area of the computer room and add temporary rotating equipment such as fan to cool down the local area. However, this method will severe increase the managers' workload, and will also pose a threat to the safe operation of the computer room.

The main reason for the difficulty in eliminating the hot pots is an unreasonable airflow distribution inside the computer room [11], which mainly manifests in local overheating caused by the mixture of cold and hot air near the IT server inlet. The 
thermal environment is the ultimate expression of the actual operation effect of the airflow organization in the computer room. Therefore, the study about the thermal environment of data centers aims to reduce local overheating, and then facilitate safe and reliable operation for it. At the same time, reducing the energy consumption is of great significance [12].

Experiment study and numerical simulation are the common methods to study the thermal environment of data center. For example, Kumar[13]et al. studied the effect of the tile air flow rate variation on the rack inlet air distribution by field experiment, which conclusion was stated that increasing the perforated tile air flow rate may not be the best way to provide cooling to high density racks. Singh[14] et al. performed experimental and numerical simulation on data center with $400 \mathrm{~kW}$ total racks power and eight CRAC units. He stated that provision of blanking panels, optimum placements of tiles in cold aisles, and increase in supply temperature from CRAC units led to $20 \%$ savings of energy cost in the data center. Fakhim[15] et al identified that the flow distribution is very complex by a computational and experimental studying in an operational data center(1400 temperature measurement points). Simulation results were in good agreement with the measurements, which can identify critical regions of hotspots.

In the study, previous researches on the thermal environment of data centers were considered can be divided into the operating parameters, airflow distribution, evaluation index, and the optimization of data center.

\subsubsection{Operating parameters}

In most air-cooled data centers, server racks are arranged into cold and hot aisles. In cold aisles, the front sides of the server racks face each other and this aisle provides cool air to each server. In hot aisles the rear sides of the racks line the aisles and the hot exhaust air exits each server here [16]. According to Patel [17] and Bash [18] et al., cold air is usually provided at $25^{\circ} \mathrm{C}$ and discharged at $40{ }^{\circ} \mathrm{C}$ for a data center with an efficient air cooling system.

Schmidt [19] et al . showed that complete separation of air circulation in cold and hot passages was very difficult, because the flow of frozen air accounted for a small part of the air flow required for the rack. Ohadi [20] et al. pointed out that in addition to hot air-cold air mixing, cold air bypass through servers were an important source of exergy loss and inefficiency in air-cooled systems.

In CRACs units, the heat returned by hot air from the rack is rejected to the outdoor, which is usually cooled by chiller and cooling tower loop. The chiller temperature will vary for different data centers. In addition to the range of temperature and humidity required by the specification in Table 1 , the detailed operation parameters of typical air-cooled data center are listed, as shown in Table 2 $[16,17,19,21-24]$. 
Table 2. Summary of typical air-cooled data center heat sources and streams[13].

\begin{tabular}{ll}
\hline Parameter & Value \\
\hline Cold aisle (CRAC supply) temp. & $10-32{ }^{\circ} \mathrm{C}$ \\
Hot aisle (CRAC return) temp. & $50-60{ }^{\circ} \mathrm{C}$ \\
Temp. rise over server & $10-20{ }^{\circ} \mathrm{C}$ \\
Airflow per rack & $200-2500 \mathrm{CFM}$ \\
Chiller water supply to CRAC & $7-10{ }^{\circ} \mathrm{C}$ \\
Chilled water return from CRAC & $35^{\circ} \mathrm{C}$ \\
\hline
\end{tabular}

*CFM represents the cubic feet per minute

\subsubsection{Airflow distribution}

The purpose of airflow distribution design is the full achievement of the cooling effect of air flow spatially with minimum energy consumption, thus preventing the mix of hot and cold airflow, while maintaining uniformity, stability, and continuity of the air flow [25].

Researchers have explored airflow distribution optimization, including the optimization of air supply and return form [7, 26-29], both optimization and adjustment of equipment layout in the computer room [30-34], and studies on the influence of air flow characteristics under raised floor [35-39].

The optimization of air supply and return form refers to the analysis of its influencing factors (e.g., the position of air supply and return, air flow direction, and air supply parameters) on the thermal environment of the computer room under a specific load. Tsuchiya [26] et al. confirmed that ceiling supply design is more robust regarding changes in major design parameters compare to floor supply design via comparing the cooling characteristics of the two designs. Huang [27] et al. compared 3 airflow patterns, i.e., under-floor air supplying system, row-level cooling system and rack level cooling system for a typical data center by CFD simulation. The results indicated that rack level airflow pattern shows the best performance in data center cooling. Oró [29] et al. examined the air management of a real data center by the use of air metrics. The results indicate that the combination of air management improvement with increasing the supply air temperature and reducing the air flow rate would allow important energy reduction in the cooling system. All the above studies goal is to optimize the airflow organization, improve the thermal environment, and reduce the energy consumption of the air conditioner via reasonable optimization of air supply and return form.

The optimization and adjustment of equipment layout in the computer room includes the optimization of the IT server, rack, air conditioner, and cold/hot aisle layout. By changing the IT server arrangement, the rack, and the air conditioner placement, the optimal cold/hot aisle width and heat source distribution are obtained. Nada [30] et al. investigated two arrangements of computer room air conditioner (CRAC) units layouts; namely locating CRACs units in line with the racks row and locating the CRACs units perpendicular to the rack row. The results showed that 
locating CRAC units perpendicular to the racks row has the following effects: (1) enhances the uniformity of the air flow from the perforated tiles along the rack row, (2) reduces the hot air recirculation at the ends racks of the row and the cold air bypass at the middle rack of the row and (3) enhances the data center performance parameters return temperature index (RTI), supply heat index (SHI) and return heat index (RHI). Zhang [33] et al. investigated a small-scale data center by combining measurement and CFD simulation. The results indicated that cold aisle closure could eliminate by-pass airflow but also worsen thermal environment. Setting air return on both sides of hot aisle got most significant improvement in cooling performance. The temperature of hot points could be decreased by $0.5-5{ }^{\circ} \mathrm{C}$. This research method is trying to identify the rules and key influencing factors of the equipment layout on the thermal environment of the computer room through the quantitative analysis of different factors. This is a passive way that improves the heat transfer efficiency by improving the airflow organization.

The influence study on characteristics of air flow under raised floor refers to the analyzed the uniformity of the thermal environment of the raised floor air supply computer room. Bhopte [36] et al. discussed the effect of plenum depth, floor tile placement, and ceiling height on the rack inlet air temperature in a raised floor data center with $12 \mathrm{~kW}$ racks. And a multivariable approach to optimize data center room layout to minimize the rack inlet air temperature is proposed. Zhang [38] et al. used computational fluid dynamic to investigate the influence of the six raised floor heights $(0.2 \mathrm{~m}, 0.4 \mathrm{~m}, 0.6 \mathrm{~m}, 0.8 \mathrm{~m}, 1 \mathrm{~m}$ and $1.2 \mathrm{~m})$ on the airflow distribution of three types of aisle condition (the open aisle, the cold aisle containment and the hot aisle containment). The recommended range of raised floor height in the data centers was obtained in Zhang's research. Due to the nonuniformity of the pressure distribution in the plenum chamber, the actual air flow rate of the perforated tile is uneven, which directly leads to an uneven air distribution in the cold aisle, thus resulting in local overheating. In this case, the study on characteristics of air flow under raised floor is particularly important for the control of the thermal environment of the computer room.

\subsubsection{Evaluation index}

The ideal thermal environment of the computer room is based on the satisfactory airflow distribution, which means that the air supply volume of the air conditioner is equal to the total demand of all IT servers. The heat transfer of cold and hot airflow is very small during the air supply and return process and can ignore them. The air inlet temperature of each server equal to the air supply temperature of the air conditioner. However, affected by various factors, the thermal environment and airflow organization always deviate from the ideal situation in the actual computer room. Consequently, problems such as cold air by-pass and hot air re-circulation often occur [40], as shown in Fig. 1. 


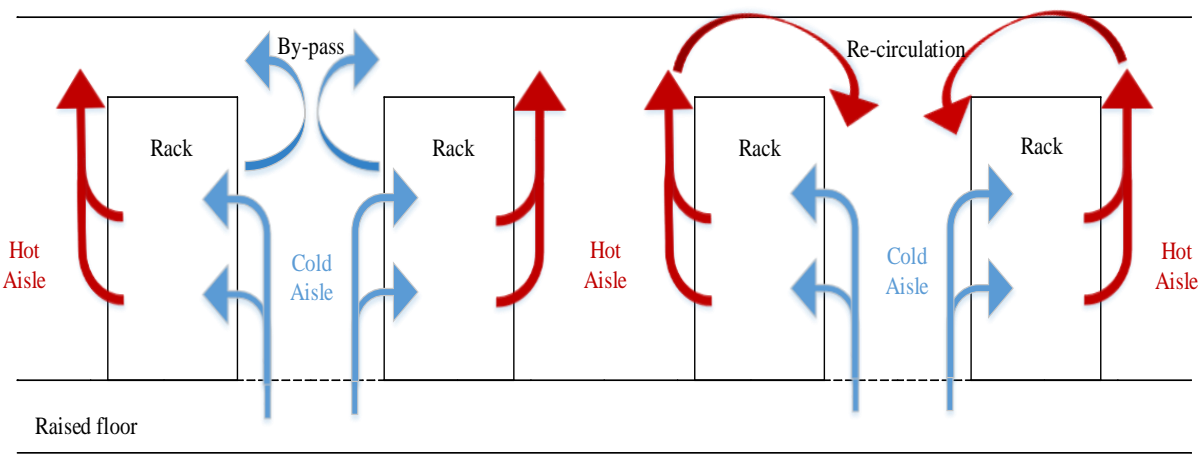

Fig. 1. Actual airflow in a computer room

Sharma [41] et al. defined two dimensionless parameters to analyze or evaluate the degree of deviation from ideal situation of actual computer rooms, SHI and RHI, with which the mixing degree of the air supply in the cold aisle can be quantified with the surrounding hot air before entering the IT server. Bash [42] et al. defined the $\beta$ index according to the SHI, which can measured the mixing degree of cold and hot air via the ratio of the average temperature rise of air inlet and the average temperature difference between the air inlet and outlet. Herrlin [43] et al. defined both rack cooling index (RCI) and RTI. The RCI is based on the recognized thermal environment standards of the computer room and it evaluates the thermal environment via statistical data of the inlet air temperature distribution of all IT servers in the computer room. Under the premise of air volume balance (the air volume demand of IT server equals to the air supply of the air conditioner), the RTI quantitatively evaluates the thermal environment and cooling system efficiency of the computer room by comparing the average inlet and outlet air temperature differences between the IT server and the air conditioner of the computer room. Table 3 shows the definition and the explanation of the thermal environment evaluation index.

Table 3. Thermal environment evaluation index

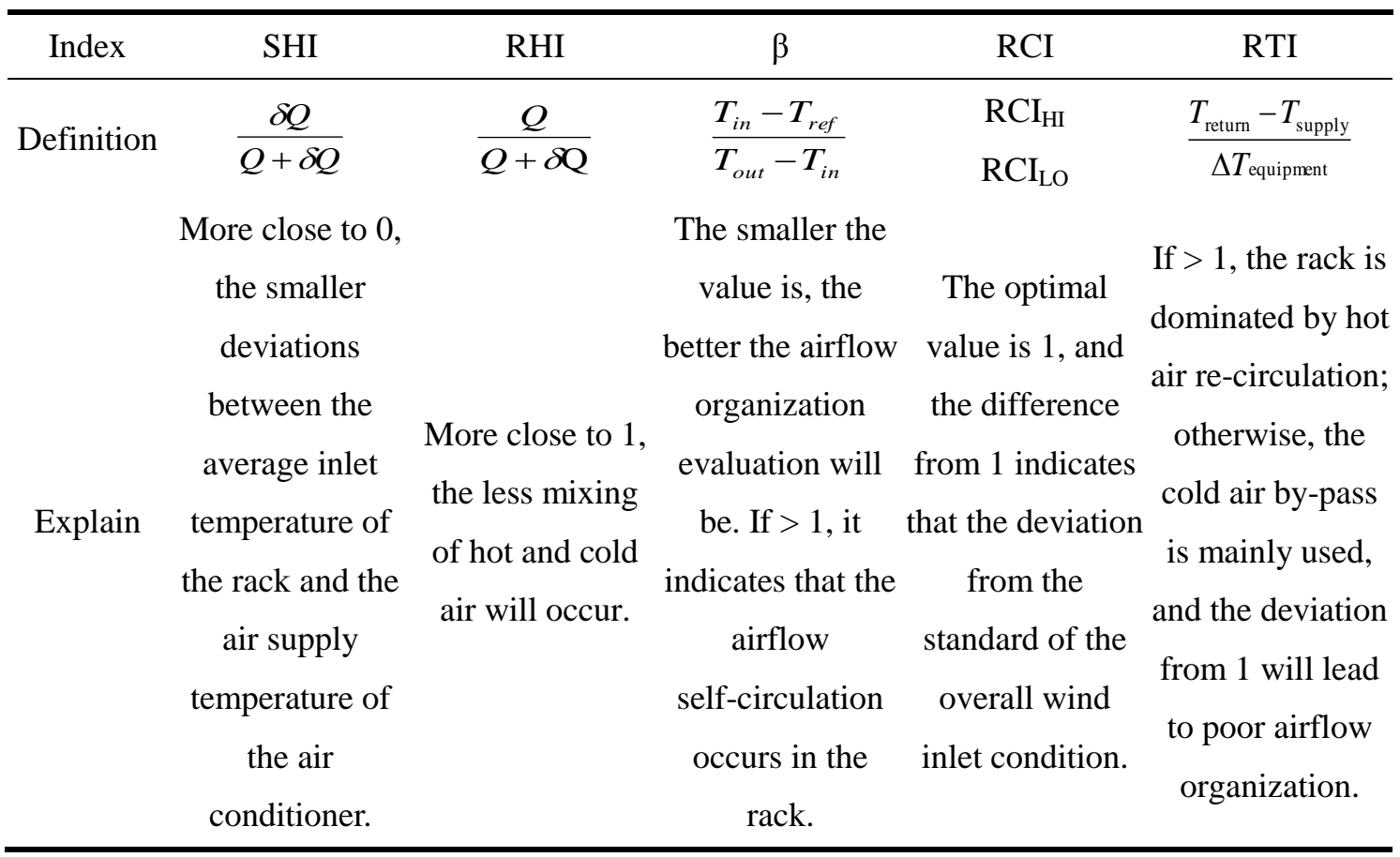




\subsubsection{Optimization of data center}

Much of the energy use by data centers is attributed to cooling, so optimizing the thermal environment of data centers can translate to direct and significant economic benefits [44]. Traditionally, energy consumption can be greatly reduced by changing the physical conditions of the data center, such as cold aisle containment and adding air guide sleeve. Recent studies have shown that improving thermal management is a shortcut to reducing energy consumption.

Yuan [45] et al. conducted experiments and simulations to investigate the impacts of server lower-side terminal baffles (SLTBs) on the optimization of airflow distribution and thermal environment in data center. The use of $45^{\circ}$ angle and $8 \mathrm{~cm}$ SLTBs can eff ectively eliminate the heat accumulation and improve the airflow distribution. Mukaffi [46] et al. optimized a data center by adding blanking panels, cold aisle containment, and changing the layout of the components and shelves. The result showed that the value of RCI achieved at $100 \%$ for $\mathrm{RCI}_{\mathrm{HI}}$ and $99 \%$ for $\mathrm{RCI}_{\mathrm{LO}}$. Meanwhile, the SHI value is reduced to 0.48 . The energy used by cooling system is also reduced by $1.28 \mathrm{~kW}$. Fouladi [44] et al. demonstrated a novel hybrid modeling strategy for efficient and accurate second law efficiency optimization of a data center cooling system using a proper orthogonal decomposition(POD) airflow modeling scheme with flow network modeling for external components. The strategy is applied to a data center cell, demonstrating energy and exergy savings of up to $23 \%$ and $43 \%$, respectively, for a data center with large server utilization. Chen [47] et al. proposed a unified management method to enable the data center to adapt to the intermittent availability of renewable energy, the variability of cooling efficiency, the change of information technology (IT) workload and the fluctuation of long-term energy prices fluctuations under long-term quality-of-service (QoS) requirements.

\subsection{Aim of the work}

Suitable thermal environment is vital for normal operation of a data center. A large number of researchers have conducted many studies on it based on experimental and numerical simulation methods, which can be summarized above. All these researches are helpful for evaluating or improving thermal environment of data centers. However, the thermal environment of data center is affected by many factors, including room area, rack arrangement. For a running data center, the problem of hot spots is also related to the location of servers. Moreover, some optimization methods are limited in actual application because of the guarantee of uninterrupted operation of data center. For example, it is generally prohibited to install the baffles during the operation time.

Therefore, how to improve the thermal environment of existed data center is an ongoing issue, which deserves to be considered and discussed continuously. In this paper, the characteristic of thermal environment in a specific data center would be studied by methods of field experiment and numerical simulation.

The object of this study, a data center, is designed to provide network support for an office building located in Wuhan city. As shown in Fig.2, Wuhan, the capital of Hubei Province, is located in the central China, whose east longitude is $113^{\circ} 41^{\prime}-115^{\circ} 05^{\prime}$, north latitude is $29^{\circ} 589^{\prime}-31^{\circ} 22^{\prime}$. It is one of the seven central cities in 
mainland, serving as the political, economic and cultural center of Hubei Province. Wuhan has the subtropical monsoon climate, and the climate is characterized by hot-summer and cold-winter, four distinct seasons, flush precipitation.

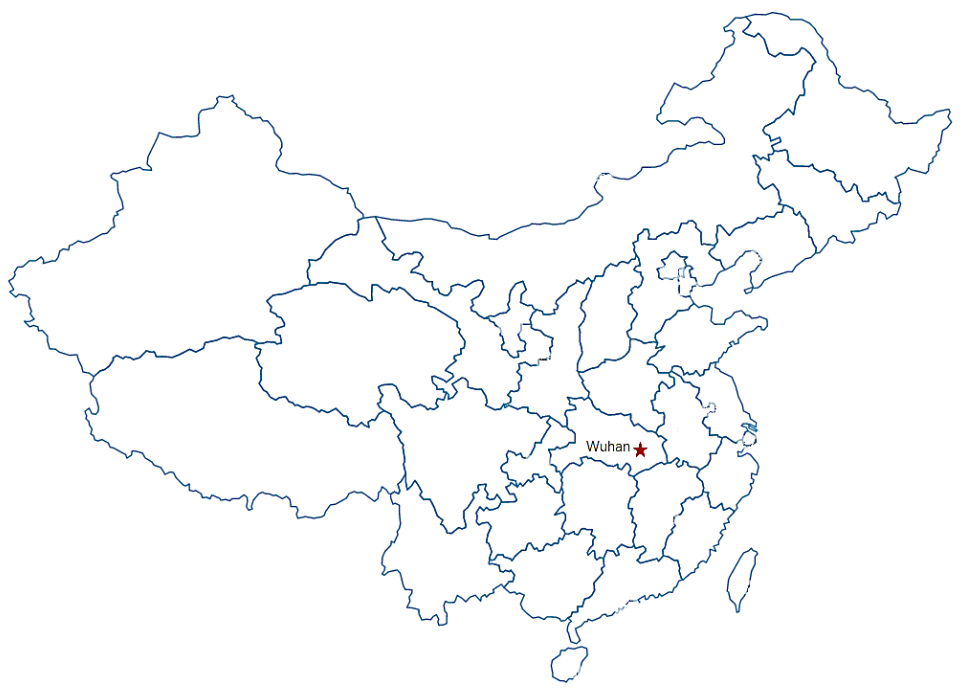

Fig. 2. Map of Wuhan's geographical location in China

As shown in Table 1, the design criteria requires temperature $20-25{ }^{\circ} \mathrm{C}$ and relative humidity $40-55 \%$. The paper mainly focuses on the former parameter but not the latter because of the favorable humid environment in this data center. The main study design is shown in Fig.3.

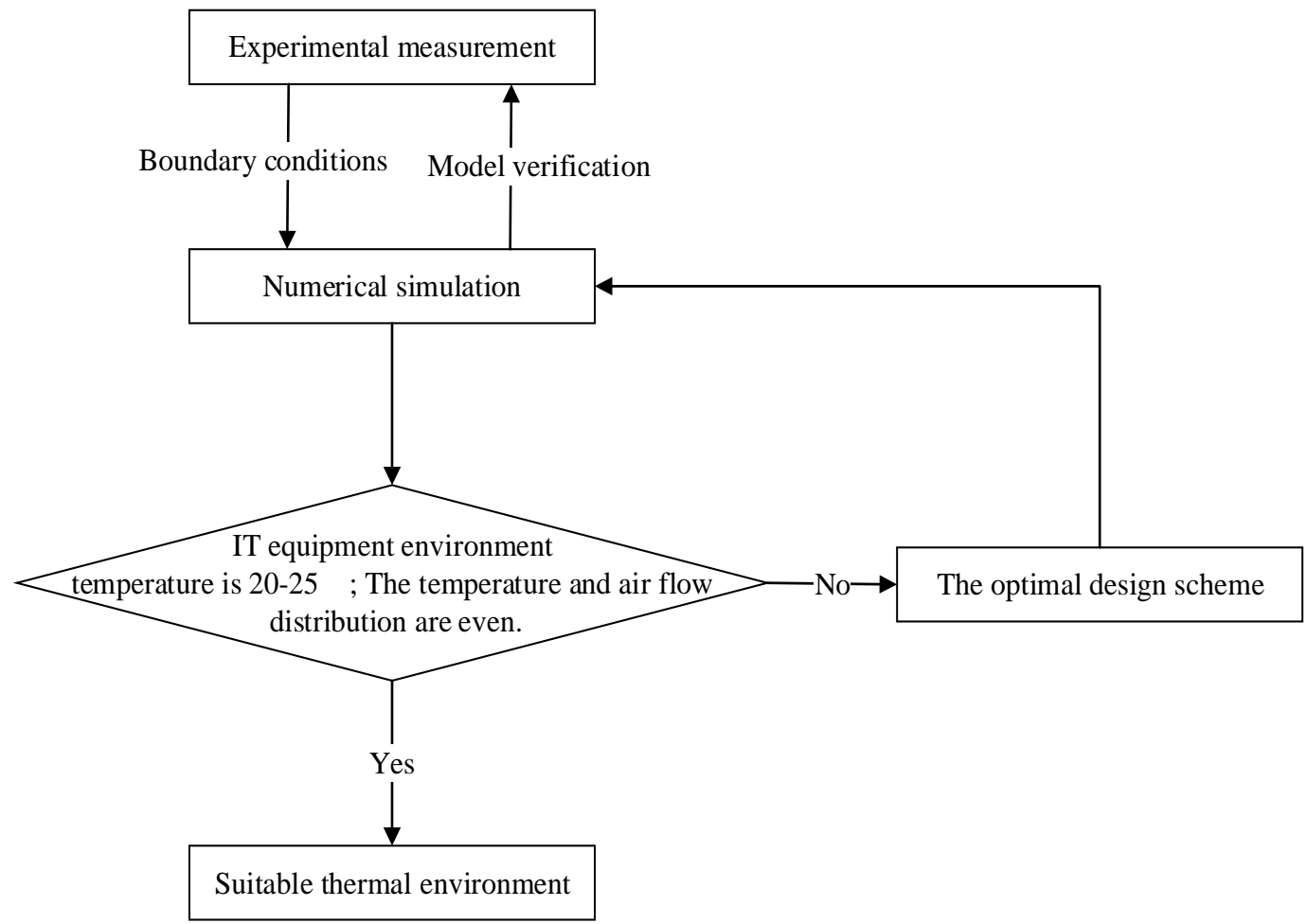

Fig. 3. Research procedure

Firstly, a field experiment was carried out to analyze the thermal environment of the data center. The wind speed and temperature of typical location in the data center 
(perforated tiles in the cold aisle, return air vent of the air conditioner, as well as inlet and outlet of the rack) were measured. Then, the thermal environment of the data center was numerical simulated by software 6SigmaRoom. The physical model and numerical calculated methods of the data center were verified to have certain feasibility because that the results of it agree well with experiment. Finally, optimization design scheme was proposed by numerical simulation. 


\section{Field Experiment}

\subsection{Summary of experiment}

The computer room is located in an office building in Wuhan, China and has two auxiliary areas. The room dimension is $14.5 \times 7.5 \times 3 \mathrm{~m}^{3}$. It adopts an air distribution form of underfloor air conditioning system (UFAC), without return air duct. The raised floor is $0.5 \mathrm{~m}$ high and the cable rack is overhead. The cod aisle is enclosed, with the width of $1.2 \mathrm{~m}$. There are 22 perforated tiles, whose size is $0.6 \times 0.6 \mathrm{~m}^{2}$ and aperture rate is $39 \%$. An underfloor air conditioning was installed with the following dimensions: $2172 \times 866 \times 1960 \mathrm{~mm}^{3}$, air outlet size of $2061 \times 324 \mathrm{~mm}^{2}$, air inlet size of $2090 \times 784 \mathrm{~mm}^{2}$, refrigerating capacity of $60.3 \mathrm{~kW}$, and air flow rate of $16030 \mathrm{~m}^{3} / \mathrm{h}$ There are 15 racks with a size of $800 \times 1060 \times 1950 \mathrm{~mm}^{3}$, which are divided into two columns (column A and, column B) with an "inlet to inlet, outlet to outlet" arrangement. The No.1 in column B is a remote power panel (RPP); the rack number and the layout of the computer room are shown in Fig. 4.

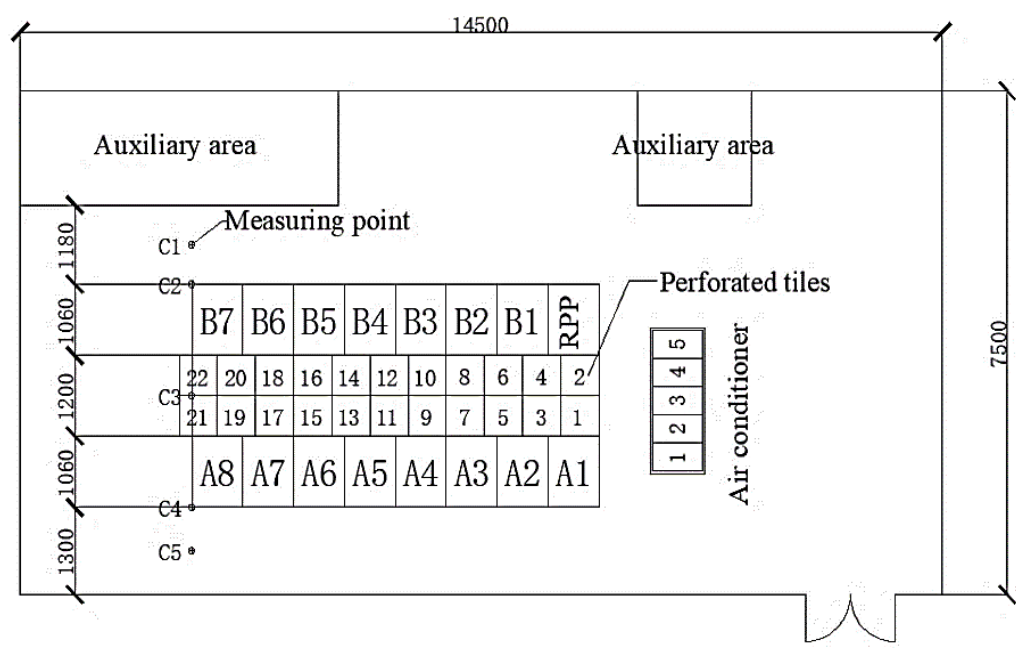

Fig. 4. Rack number and layout of the computer room

Selecting the stable running time of the computer room, the geometric dimension of the computer room was measured as well as the wind speed and temperature of typical location. Wind speed and temperature recorder were used to collect data. The thermal imager was used to record the heat distribution on the surface of the equipment in the computer room. Before being measured, the testing instrument was calibrated. The performance parameters are shown in Table 4.

Table 4. Summary of instruments

\begin{tabular}{cccc}
\hline Name & Type & Range & Accuracy \\
\hline Wind speed and temperature & WFWZY-1 & $-20-80{ }^{\circ} \mathrm{C}$ & $\pm 0.01{ }^{\circ} \mathrm{C}$ \\
recorder & & $0.05-30 \mathrm{~m} / \mathrm{s}$ & $\pm 0.01 \mathrm{~m} / \mathrm{s}$ \\
Thermal imager & Flir-B425 & $-20-120{ }^{\circ} \mathrm{C}$ & $\pm 0.1^{\circ} \mathrm{C}$ \\
\hline
\end{tabular}

The distribution of measuring points is shown in Table 5. In this experiment, the average value has been taken as the test value after five-time measurements. 
Table 5. Layout of measuring points

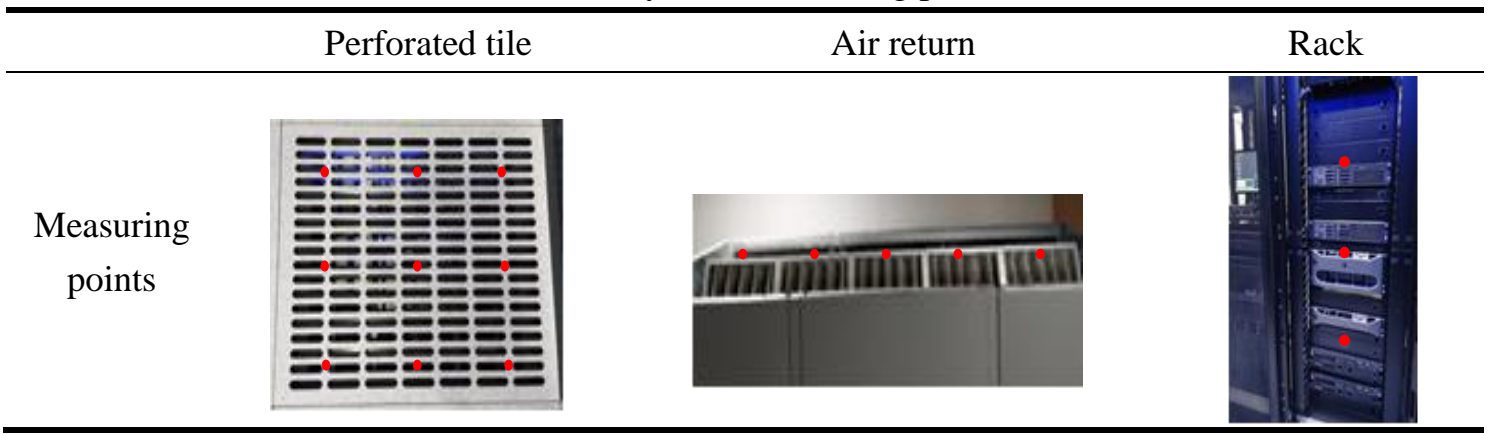

2.2 Experimental results and analysis

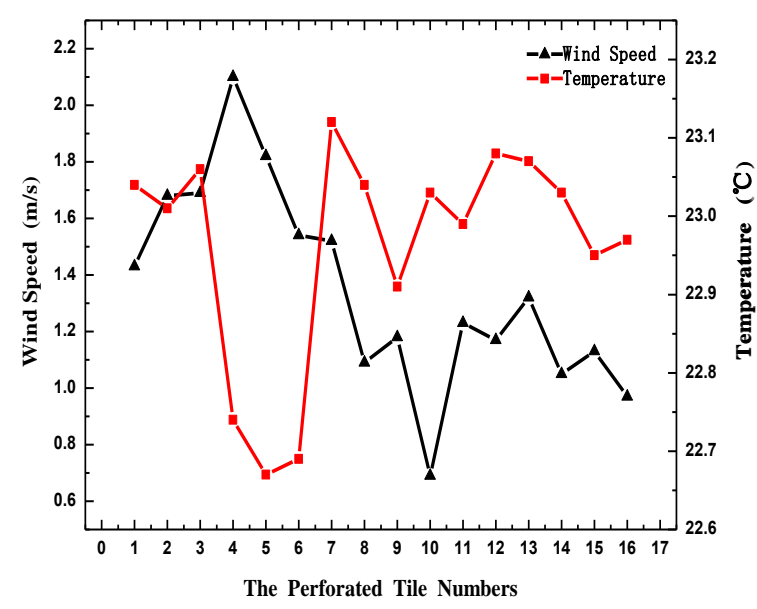

(a) The results of perforated tile

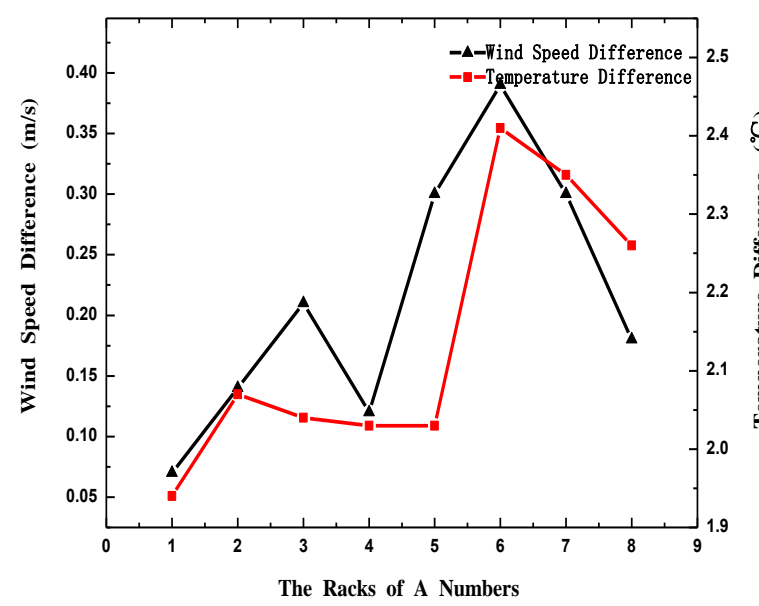

(c) The results of racks of $\mathrm{A}$

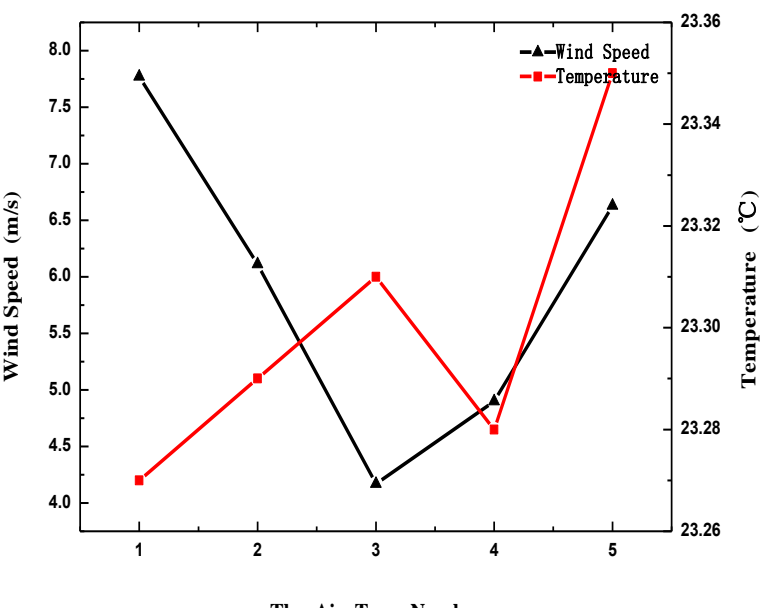

(b) The results of air turn

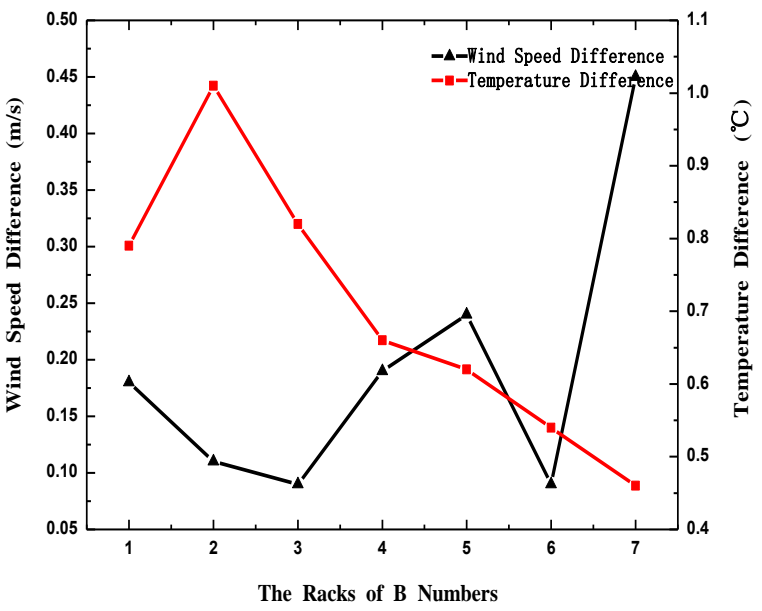

(d) The results of racks of $B$

Fig. 5. Wind speed and temperature of field experiment

The experimental results are shown in Fig. 5. As total of 22 perforated tiles were arranged in the cold aisle of the computer room and were numbered according to their distance from the air outlet of air conditioner, as shown in Fig. 4. As the No.17 to No.22 perforated tiles are not used on actual condition, the air outlet of the No.1 to No.16 perforated tiles were taken to measure in the experiment. From the Fig.5 (a) shows that the air supply temperature in the cold aisle of the computer room remains 
relatively stable, at about $23{ }^{\circ} \mathrm{C}$. The wind speed fluctuates greatly in the cold aisle, and the air velocity at the air conditioner outlet is low. With increasing air supply distance, the general trend of the wind speed increases first and then decreases. When the air is supplied under the raised floor, the space under the raised floor is equivalent to plenum chamber that is a crucial part of air supply system to reduce dynamic pressure, increase static pressure, stabilize airflow and reduce airflow vibration. The air velocity of the perforated tiles near the air conditioner is low because the backflow area is formed in the air conditioner outlet, and dynamic pressure is rapidly consumed in the rotation process. With increasing air supply distance, the dynamic pressure of air flow gradually converted into static pressure due to the effect of plenum chamber, then the speed of air flow gradually decreases. The most far away from the air conditioner outlet, the air flow becomes nearly stagnant.

The results of this experiment show that the wind speed of No.8 and No.10 perforated tiles suddenly decrease. During the experiment, the valves under the perforated tiles No.8 and No.10 were not fully opened, and the opening ratio was about $25 \%$. As the opening area of valves decreases, the resistance of it increases, leading to a decrease of the wind speed and an increase of the corresponding temperature. These experimental results indicate that the air outlet of the perforated tiles of No.4 and No.5 have higher wind speed, lower temperature, and better cooling capacity, therefore can support more IT server to work.

From the Fig.5 (b) shows that the wind speed in the return air area of the computer room changes dynamically. The maximum value is $9.99 \mathrm{~m} / \mathrm{s}$ and the minimum one is $3.55 \mathrm{~m} / \mathrm{s}$ while the temperature is relatively stable at about $23.30^{\circ} \mathrm{C}$. In summary, the return wind speed is lower and the temperature is higher in the middle part compared to both sides of the air return area.

The difference of wind speed between the inlet and the outlet of the rack reflects the resistance of the IT server in the rack on the air flow. The greater this difference is, the greater the resistance will be. The difference of air temperature between the inlet and the outlet of the rack can reflect heat dissipation of IT server. The bigger the difference is, the higher the heat dissipation of the server will be. The results of Fig.5 (c) and Fig.5 (d) show that there is no great difference for the wind speed between column $\mathrm{A}$ and $\mathrm{B}$, while there is apparent difference for the air temperature between them. A's temperature difference exceeds B's, which shows that the heat dissipation of the server is higher in the column A than B. 
Table 6. Infrared thermography images of the computer room

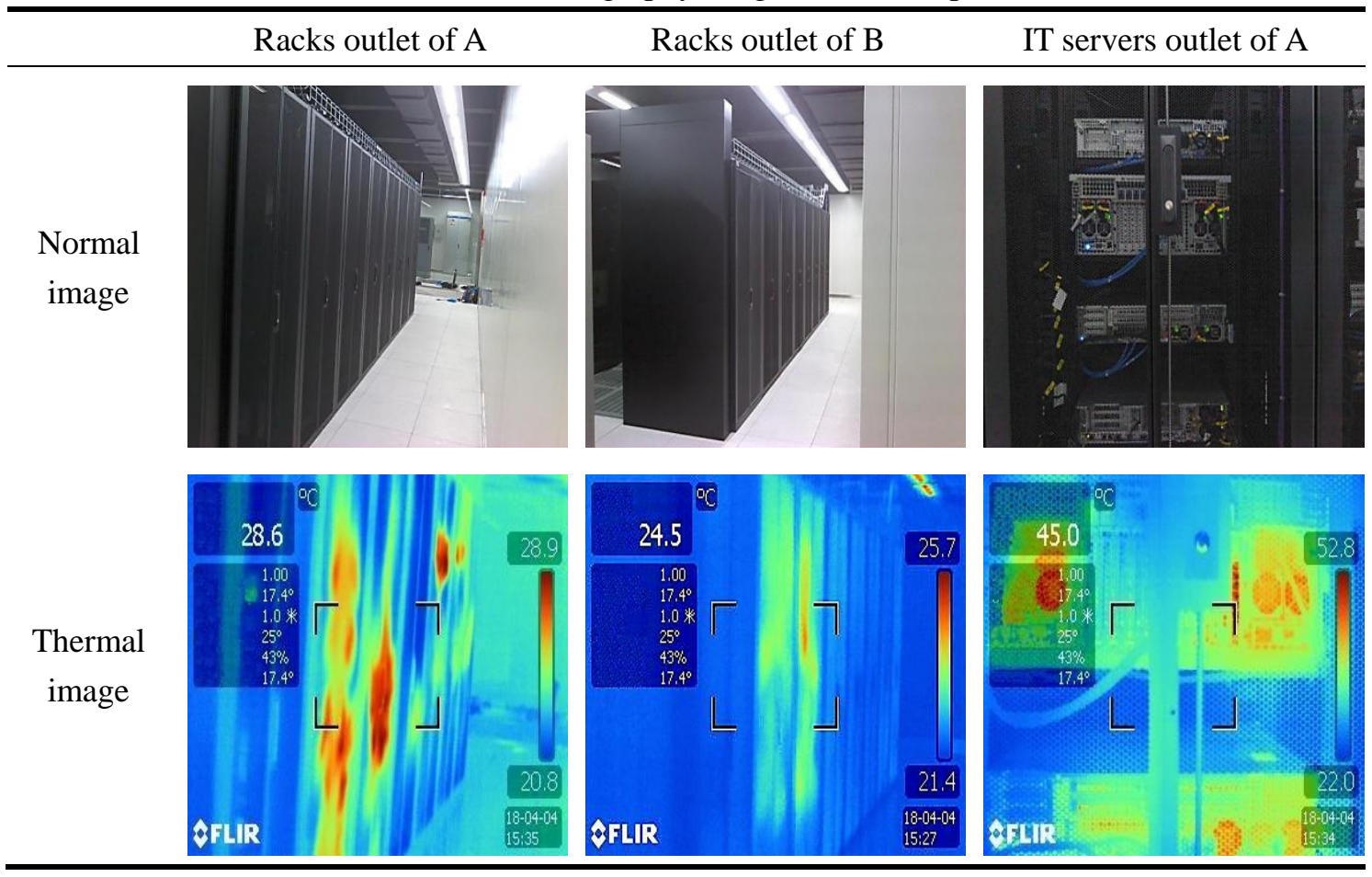

To better reflect the heat distribution on the surface of the equipment in the computer room, a thermal imager was used to measure surface temperature. Table 6 shows the infrared thermography images of the computer room. A local overheating situation exists at the rack outlets of $\mathrm{A}$ and $\mathrm{B}$, and the problem of $\mathrm{A}$ is more severe. From Table 6, it can be found that the local temperature of the IT server reaches up to $45^{\circ} \mathrm{C}$, which severely threatens the normal operation of the equipment. Therefore, the thermal environment of the computer room needs to be improved.

2.3 Measurement uncertainty evaluation

The uncertainty, which may caused by the accuracy of instrument and measuring points and the interference of personnel, is an important factor to evaluate the rationality of experiment. From the Fig.5(c) shows that No.6 rack in A column has the largest difference in wind speed and temperature, where is the high-incidence area of exorbitant temperature. Therefore, taking the outlet of No.6 rack in A column as an example, uncertainty analysis was carried out on the measurement results of wind speed and temperature.

The type A standard uncertainty refers to the calibration of standard uncertainty by statistical analysis:

$$
u_{A}=\frac{s}{\sqrt{n}}
$$

Where $S$ is the standard deviation defined by Bessel Formula and $n$ is the number of measurements.

$$
S=\sqrt{\frac{\sum\left(x_{i}-\bar{x}\right)^{2}}{n-1}}
$$

The type A standard uncertainty via calculation are shown in Table 7. 
Table 7.The type A standard uncertainty of the outlet of No.6 rack

In this experiment, the main reason for the type B uncertainty is that the measuring instrument should have a confidence probability close to $100 \%$ considering that the instrument error is allowable. Therefore, the instrument error can be directly evaluated as the type B uncertainty. According to Table 4, the type B uncertainty of wind speed measurement is $0.01 \mathrm{~m} / \mathrm{s}$, and the type B uncertainty of temperature measurement is $0.01{ }^{\circ} \mathrm{C}$.

The combined standard uncertainty is an estimate of the standard deviation of the measurement results:

$$
u_{C}=\sqrt{u_{A}^{2}+u_{B}^{2}}
$$

The combined standard uncertainty via calculation are shown in Table 8 .

Table 8. The combined standard uncertainty of the outlet of No.6 rack

\begin{tabular}{ccc}
\hline & Wind speed $(\mathrm{m} / \mathrm{s})$ & Temperature $\left({ }^{\circ} \mathrm{C}\right)$ \\
\hline Upper part & 0.096 & 0.336 \\
Middle part & 0.083 & 0.310 \\
Under part & 0.105 & 0.335 \\
\hline
\end{tabular}

As can be seen from the above calculation results, the combined uncertainty of wind speed ranges from $0.096 \mathrm{~m} / \mathrm{s}$ to $0.105 \mathrm{~m} / \mathrm{s}$, while the temperature is $0.310^{\circ} \mathrm{C}$ to $0.336^{\circ} \mathrm{C}$ The relative measurement uncertainty for temperature via calculation is within $1.3 \%$ (less than 5\%)[48]. According to Nadjahi et al[49] and Yuan et al[50], the dispersion of the results is small compared with the measured value, which is close to the truth value with suitable accuracy. 


\section{Numerical simulation and validation}

\subsection{Physical model and computational settings}

According to the computer room layout, the physical model was established via CFD simulation software 6SigmaRoom, as shown in Fig. 6. The simulation software 6SigmaRoom is quotes from fluent of the calculation method, which can numerically calculate and analyze the thermal environment for existing computer room systems, thus help the managers to reduce possible risks effectively. In addition to this, the process of modeling is more convenient and quick due to the fact that there are some modules of the data center in simulation software 6SigmaRoom, therefore it is now widely used [10], [11], [25], [28], [33].

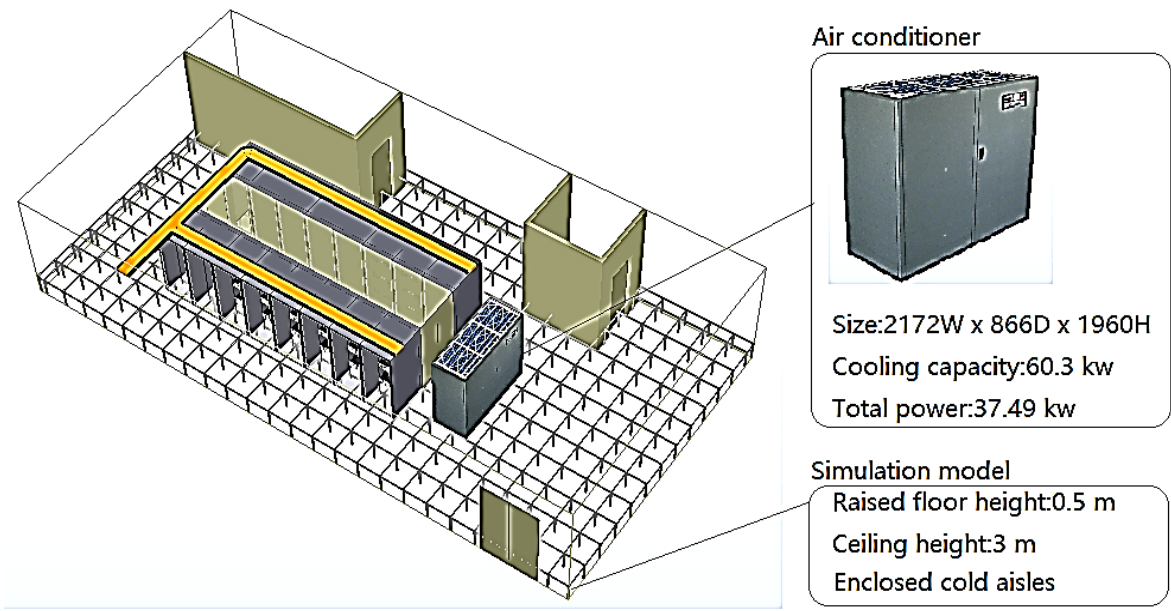

Fig. 6. Computer room model

A dedicated air conditioner for underfloor air supply is installed in the room. The return air outlet is located at the top of it. The air-cooled direct expansion unit with R22 as refrigerant is adopted. When the computer room is working, the air conditioner absorbs heat from the room and transfers it to the outdoor air through an air-cooled heat exchanger. Because of continuous operation, the calorific value of air conditioner is much less than that of the IT server, which can be neglected in this paper. Therefore, the air conditioner cooling load Q is the sum of the IT server load Q1 and the environmental load Q2, as shown in Equation (4).

$$
Q=Q_{1}+Q_{2}
$$

The IT server load in the computer room can be determined via the following calculation. $Q_{2}$ represents the heat gain through the enclosure structure, personnel, and lighting. In this paper, the computer room is located inside the office building with only one external wall. The external wall has good thermal insulation performance, and the computer room is intelligently controlled. Moreover, the other indoor heat gain can be ignored because of few indoor activities. Therefore, the air conditioner cooling load $Q$ is approximately equal to the IT server load $Q_{l}$.

Then the air conditioner cooling load $Q$ can be calculated according to the Equation (5).

$$
Q=C q_{v} \rho\left(T_{\text {in }}-T_{\text {out }}\right)
$$


where $C$ represents the air specific heat capacity at constant pressure, that can be considered as $1.01 \mathrm{~kJ} /\left(\mathrm{kg} \cdot{ }^{\circ} \mathrm{C}\right) ; q_{v}$ represents the air flow rate, that can be taken as $16030 \mathrm{~m}^{3} / \mathrm{h} ; \rho$ represents the density, $1.2 \mathrm{~kg} / \mathrm{m}^{3} ; T_{\text {in }}$ and $T_{\text {out }}$ represent the supply temperature and return temperature of the air conditioner respectively and uses the experimental results of supply and return temperature of air conditioner, $22.97{ }^{\circ} \mathrm{C}$ and $23.30{ }^{\circ} \mathrm{C}$. $Q$ is calculated to be $1.78 \mathrm{~kW}$ in this case.

The IT server is only placed in the rack of A1-A6 and B1-B2 based on the actual situation of the computer room. Moreover, to facilitate simulation, the IT server is uniformly arranged into the upper part, middle part, and under part in the rack, as shown in Fig. 7. After calculation, each IT server load was set to $74 \mathrm{~W}$.

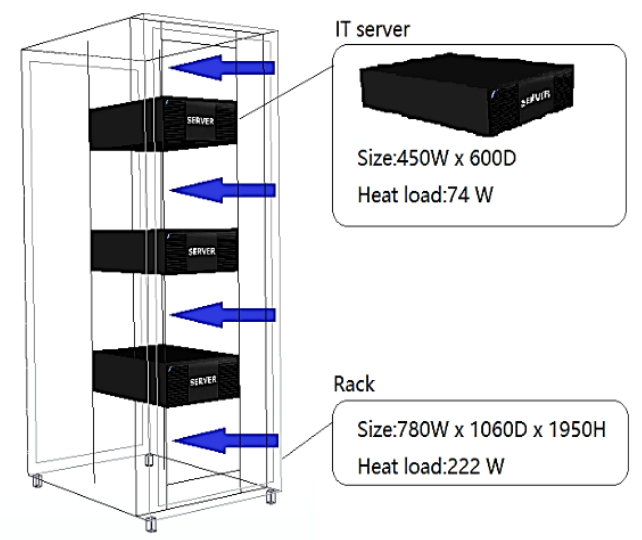

Fig. 7. Rack model

According to the experimental results, the aperture rate of the perforated tile was $39 \%$, and the valve opening under the perforated tile was $50 \%$. As the valves under the perforated tiles of No.8 and No.10 are partially open, they are set to $25 \%$. The valves under the perforated tile of No.17 to No.22 are closed, so they are set to $5 \%$, considering leakage.

\subsection{Governing equations}

Mathematical equations are the basis of any numerical simulation. In this paper, it is assumed that the flow field in the data center satisfies Bernoulli Hypothesis, which is based on the mass conservation equation, the momentum conservation equation, and the energy conservation equation [48].

For incompressible fluids, the mass conservation equation is:

$$
\frac{\partial u}{\partial x}+\frac{\partial v}{\partial y}+\frac{\partial \omega}{\partial z}=0
$$

The momentum conservation equation is:

$$
\begin{gathered}
\frac{\partial u}{\partial t}+u \frac{\partial u}{\partial x}+v \frac{\partial u}{\partial y}+\omega \frac{\partial u}{\partial z}=v\left(\frac{\partial^{2} u}{\partial x^{2}}+\frac{\partial^{2} u}{\partial y^{2}}+\frac{\partial^{2} u}{\partial z^{2}}\right)-\frac{1}{\rho} \frac{\partial p}{\partial x}+X \\
\frac{\partial v}{\partial t}+u \frac{\partial v}{\partial x}+v \frac{\partial v}{\partial y}+\omega \frac{\partial v}{\partial z}=v\left(\frac{\partial^{2} v}{\partial x^{2}}+\frac{\partial^{2} v}{\partial y^{2}}+\frac{\partial^{2} v}{\partial z^{2}}\right)-\frac{1}{\rho} \frac{\partial p}{\partial y}+Y \\
\frac{\partial \omega}{\partial t}+u \frac{\partial \omega}{\partial x}+v \frac{\partial \omega}{\partial y}+\omega \frac{\partial \omega}{\partial z}=v\left(\frac{\partial^{2} \omega}{\partial x^{2}}+\frac{\partial^{2} \omega}{\partial y^{2}}+\frac{\partial^{2} \omega}{\partial z^{2}}\right)-\frac{1}{\rho} \frac{\partial p}{\partial z}+Z
\end{gathered}
$$

The energy conservation equation is:

$$
\rho\left(\frac{\partial T}{\partial t}+u \frac{\partial T}{\partial x}+v \frac{\partial T}{\partial y}+\omega \frac{\partial T}{\partial z}\right)=\frac{\lambda}{c_{p}}\left(\frac{\partial^{2} T}{\partial x^{2}}+\frac{\partial^{2} T}{\partial y^{2}}+\frac{\partial^{2} T}{\partial z^{2}}\right)+S_{T}
$$


The standard $\kappa-\varepsilon$ model of turbulence calculation for high Reynolds numbers is selected, that is the default calculation model of simulation software 6SigmaRoom. Its equations are shown in the following.

The turbulent kinetic energy equation is:

$$
\rho \frac{\partial \kappa}{\partial \mathrm{t}}+\rho u_{i} \frac{\partial \kappa}{\partial x_{i}}=\frac{\partial\left[\left(\mu+\frac{\mu_{t}}{\sigma_{\kappa}}\right) \frac{\partial \kappa}{\partial x_{j}}\right]}{\partial x_{j}}+G_{\kappa}-\rho \varepsilon
$$

The turbulent dissipation rate equation is:

$$
\rho \frac{\partial \varepsilon}{\partial \mathrm{t}}+\rho u_{i} \frac{\partial \varepsilon}{\partial x_{i}}=\frac{\partial\left[\left(\mu+\frac{\mu_{t}}{\sigma_{\varepsilon}}\right) \frac{\partial \varepsilon}{\partial x_{j}}\right]}{\partial x_{j}}+C_{1 \varepsilon} \frac{\varepsilon}{\kappa} G_{\kappa}-C_{2 \varepsilon} \rho \frac{\varepsilon^{2}}{\kappa}
$$

The kinematic viscosity $\mu_{t}$ can be obtained using the following equations:

\subsection{Model validation}

$$
\mu_{t}=\rho C_{\mu} \frac{\kappa^{2}}{\varepsilon}
$$

To verify whether the settings of the boundary conditions of the model can meet the engineering practice, five measuring points $(\mathrm{C} 1, \mathrm{C} 2, \mathrm{C} 3, \mathrm{C} 4$, and $\mathrm{C} 5$, as shown in Fig. 4.) were investigated. In the previous experiment, the wind speed and temperature at different heights $(0.5 \mathrm{~m}, 1.0 \mathrm{~m}, 1.5 \mathrm{~m}$, and $2.0 \mathrm{~m}$ away from the raised floor) of these points have been measured. Then, the data of those points are obtained from the numerical simulation. Table 9 shows the detailed information.

Table 9 shows the wind speed and temperature variation of the measured and the simulated results. In point of $\mathrm{C} 1$, the measured and the simulated results are very close, and the maximum relative deviations of temperature are all below $0.78 \%$. Similarly, the deviations of wind speed and temperature in five points are shown in Fig. 8. According to the Fig. 8, the relative deviations of temperature between measured data and simulated results range from $0.22 \%$ to $4.29 \%$, while the wind speed is $1.12 \%-11.33 \%$.

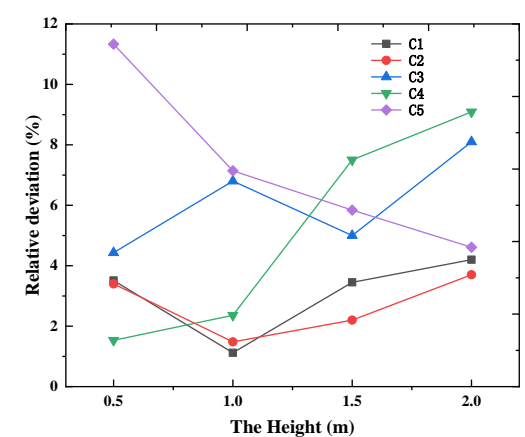

(a) Relative deviation of wind speed

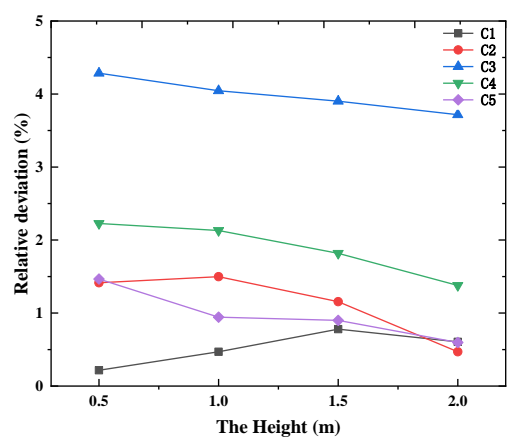

(b) Relative deviation of temperature

Fig. 8. Relative deviation of 5 points between the experimental and numerical results

In addition, it can be seen form Table 9, that the measured and the simulated results of the same point follow the same rules of change, the wind speed and temperature is decreases and increases respectively as the height increases. The measured and the simulated results shows the same trend of that the closer the point is to the cooling channel, the higher the wind speed is. 
Due to the influence of the external environment and usage, the heat dissipation of equipment in the computer room has characteristics of dynamic changes, which had been regarded as a steady-state process in the simulation. Moreover, in the numerical simulation, the influence of external environment and heat dissipation of air conditioner were neglected. In the field experiment, the results were also affected by the interference of the activities of the surveyors and the errors of the measuring instrument system. These are the main reasons for deviation between simulated results and measured. Nevertheless, the trend of variation between simulated and measured values is basically the same, and the relative deviation is small. Therefore, it can be concluded that the physic model, the boundary conditions settings, and the calculated method are reasonable and it can meet the needs of an engineering simulation. 
Table 9. Comparison of measured and simulated values

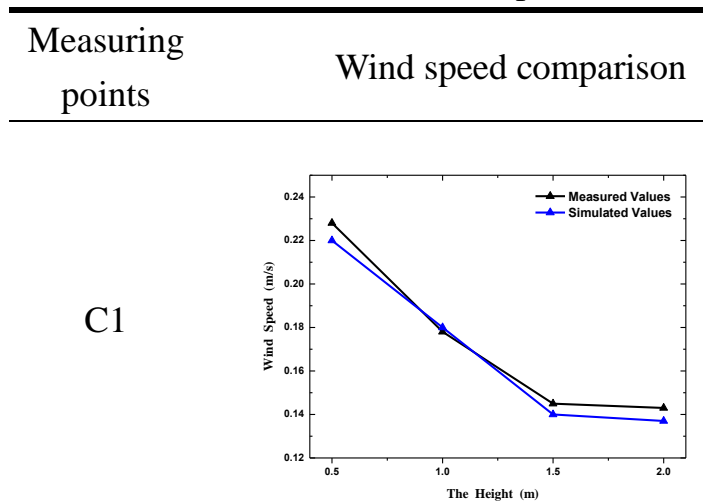

Temperature comparison
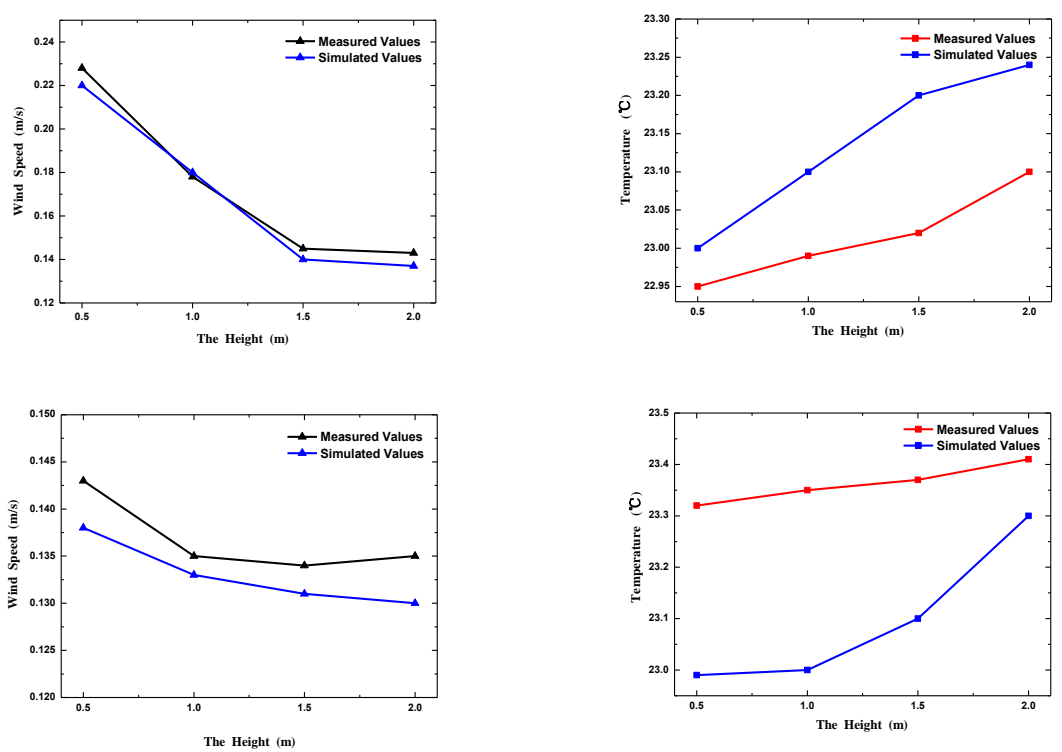

C3
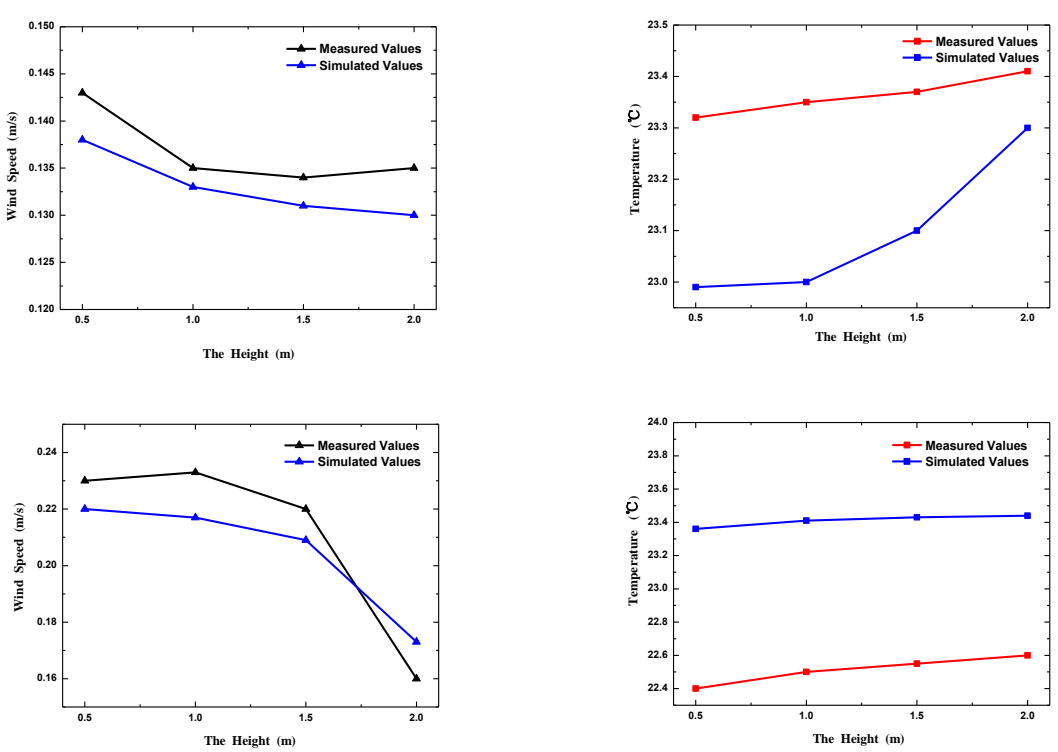

C4
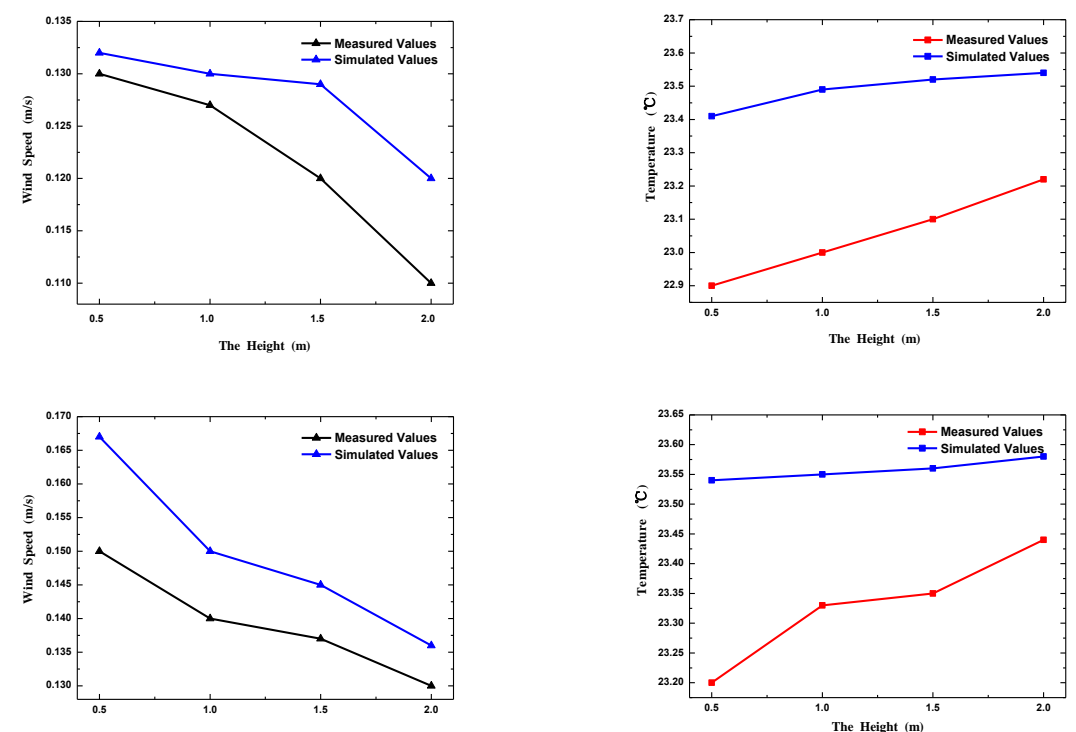


\section{Discussion and optimization design}

\subsection{Simulation results analysis}

Table 10. Temperature distribution of racks

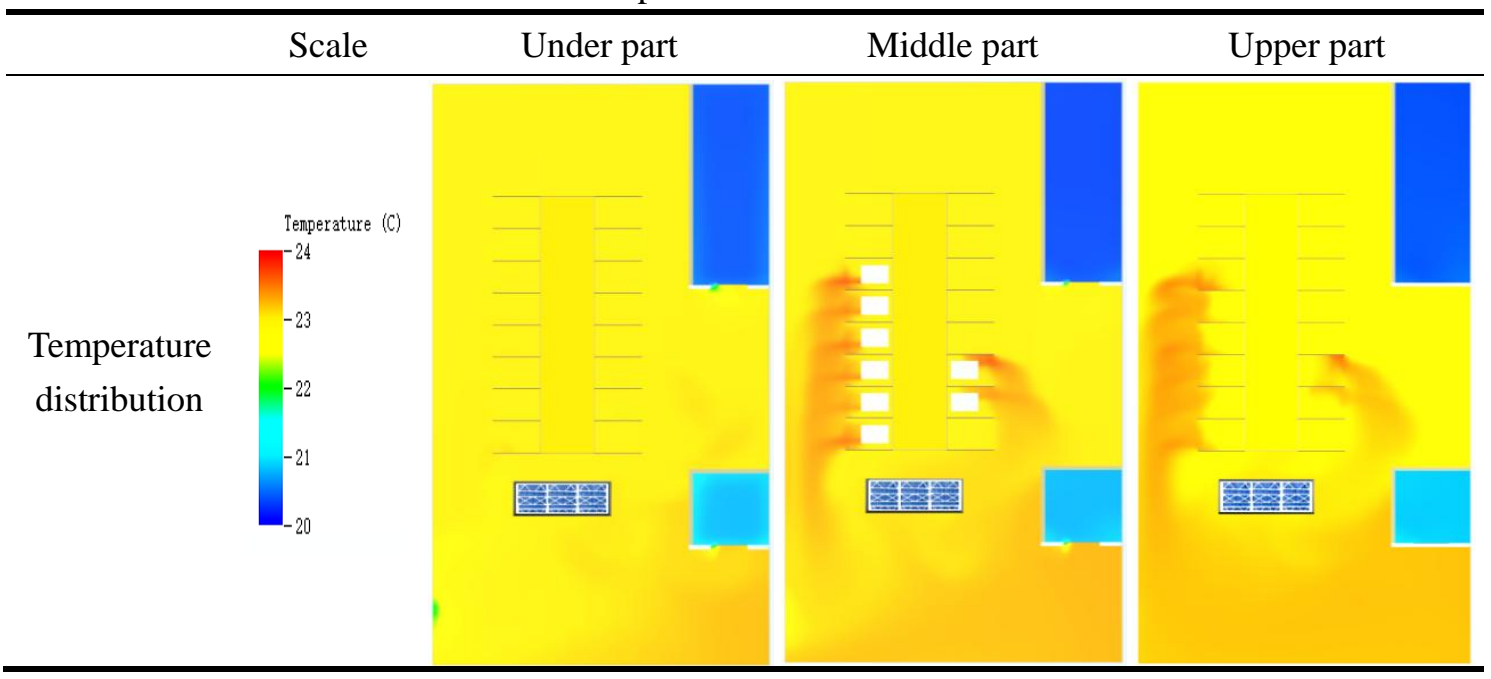

To better reflect the working environment of the IT servers in the computer room, the temperature distribution at the under part, middle part, and upper part of the racks were selected, as shown in Table 10. It can be seen from the Table 10, hotspots are obvious, especially in racks of column A. The outlet temperature of rack increases firstly and then decreases with the increase of height, as the same trend with experimental results.

The ambient temperature of the computer room is about $23{ }^{\circ} \mathrm{C}$. The temperature distribution at the under part of the racks is even because the underfloor air supply has been adopted. However, in the middle part and upper part of the racks, the temperature is higher and more uneven at the outlet of the IT server.

Table 11. Streamline distribution

\begin{tabular}{lll|}
\hline & Air flow in the cold aisle & Air flow around air conditioner \\
\hline $\begin{array}{l}\text { Streamline } \\
\text { distribution }\end{array}$ &
\end{tabular}

Streamline is a space curve drawn in the flow field at a specific time and the density of streamline reflects the velocity in the flow field at that time. Table 11 shows the streamline distribution of the air flow in the cold aisle and around the air conditioner. The problem of uneven streamline distribution appeared in the cold aisle. It can be found that only the wind speeds of No.1 and No.3 to No.8 is large at the perforated tiles while the other wind speeds are small. The streamline of air flow around the air conditioner forms vortexes on both sides. In the process of vortex formation, the cold air consumes kinetic energy and cannot enter the racks to cool the 
IT server, which results in a loss of cooling capacity.

\subsection{Optimization method}

The above analysis shows that uneven temperature distribution and chaotic air supply exist in the data center. As seen from the practical application in the data center, parts of the empty slots in the racks were open and the valves under the perforated tile of the racks with IT server were not fully opened. Considering the above problems, the following optimized design schemes are proposed on the premise of no major changes:

(1) All empty slots of the racks should be closed.

(2) The valves under the perforated tile of the racks with the IT server should be fully opened, and the valves without IT server should be closed.

(3)Air guide sleeve should be installed on the air outlet of the air conditioner, which is shown in Fig.9.

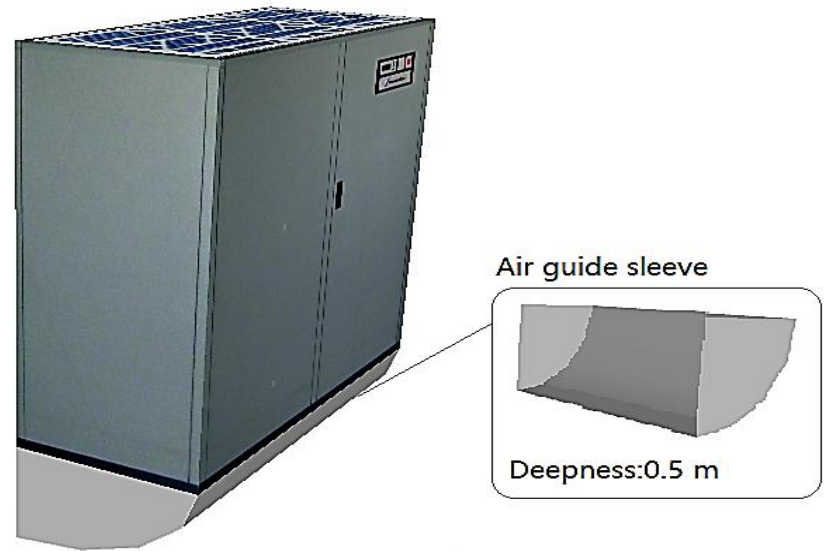

Fig. 9. Installation diagram of air guide sleeve

\subsection{Comparison and analysis}

The main reason for the uneven temperature distribution in the computer room is the heat produced during the operation of the IT server is not removed fully due to unreasonable air distribution, which leads to a high temperature at the position of the IT server. A comparison of the numerical simulation results before and after optimization, are shown in Table 12. No matter it is A or B, the comparison shows that the temperature at the position of the IT server is noticeably reduced after optimization, and the temperature distribution is more uniform. The thermal environment is more conducive for the stable operation of the IT server.

As shown in Table 11, the streamline distribution of the air flow around air conditioner in the computer room was chaotic and uneven. To solve the above problems, a curved air guide sleeve in depth $0.5 \mathrm{~m}$ is added to the air conditioner outlet, which is enclosed on the left and right, with the opening oriented towards the rack. Comparing the results before and after optimization, it shows that the air supply flow of the air conditioner is more orderly after the optimization design in Table 12; furthermore, air flows directly into the cold aisle, fully utilizing the cooling capacity. It also can be seen that the air flow in the cold aisle is more uniform after adjusting the valves under the perforated tile. 


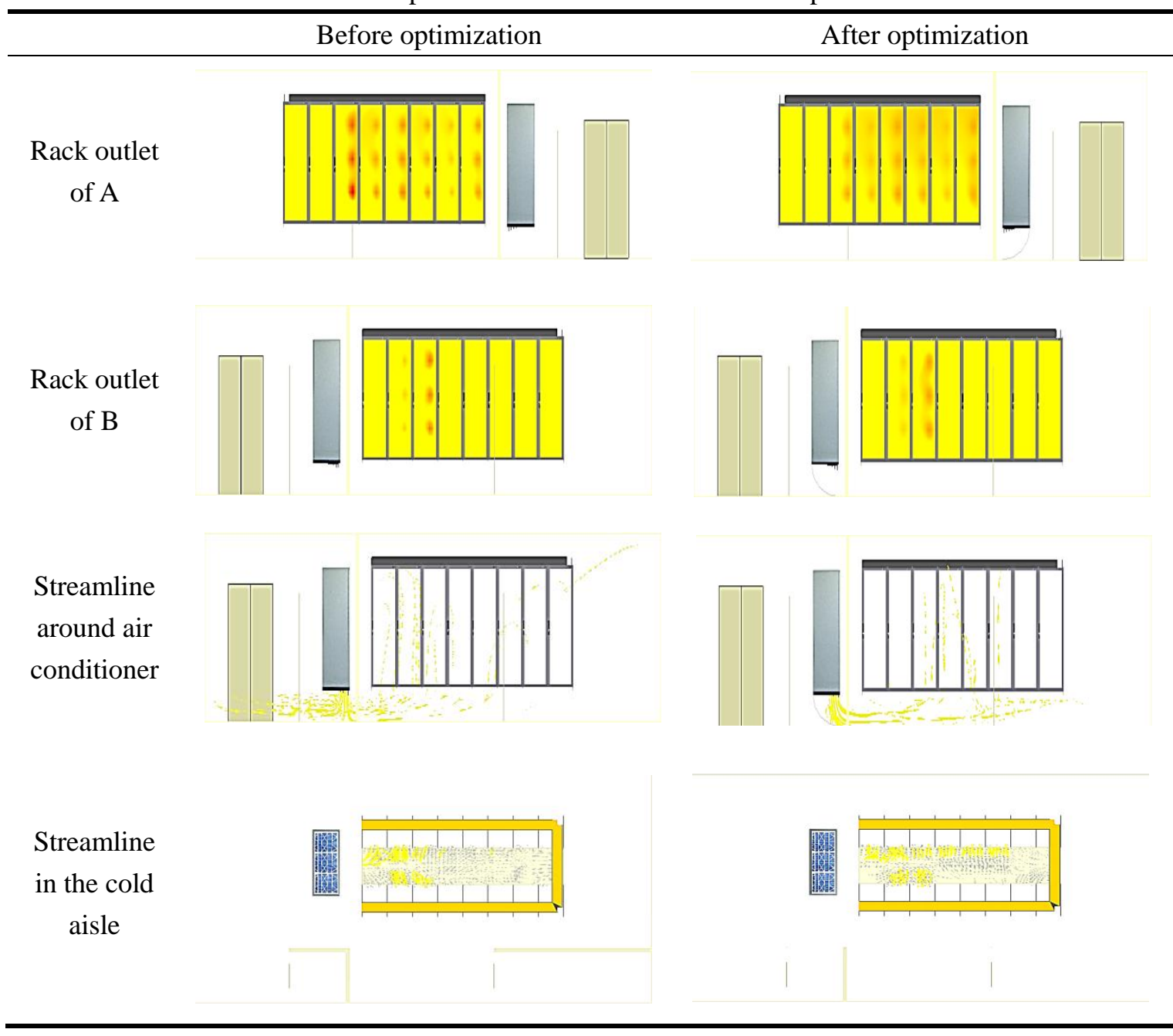

Table 13 shows the thermal environment evaluation indexes of the computer room before and after optimization. The RCI before and after optimization is 1 , which indicates that the inlet air temperature of rack is in the range of stipulated temperature by ASHRAE. After optimization, SHI decreases while RHI and RTI increases. The results show that the average inlet temperature of the rack is closer to the air supply temperature of the air conditioner, the mixing of cold and hot air is reduced, and the air supply efficiency is improved. At the same time, the problem that by-pass of cold air is solved partly. Therefore, it can be concluded that the thermal environment of the data center can be effectively improved by applying optimization method proposed in part 4.2.

Table 13. Thermal environment evaluation index of the computer room

\begin{tabular}{ccccc}
\hline Index & SHI & RHI & RCI & RTI \\
\hline $\begin{array}{c}\text { Before } \\
\text { optimization design }\end{array}$ & 0.00051 & 0.918 & 1 & 0.222 \\
$\begin{array}{c}\text { After } \\
\text { optimization design }\end{array}$ & 0.00004 & 0.93 & 1 & 0.342 \\
\hline
\end{tabular}




\section{Conclusions}

The thermal environment of an existed typically data center located in Wuhan, China, was analyzed by field experiment and numerical simulation. The simulation model was validated by field experiments, while the experimental results are in good agreement with numerical results. The main conclusions of the paper are as follows:

(1) It is found that the air velocity at the air conditioner outlet is low. With increasing air supply distance, the general trend of the wind speed increases first and then decreases. The perforated tiles of No.4 and No.5 have higher wind speed, lower temperature, and better cooling capacity.

(2) Several optimization methods were proposed to improve thermal environment of the existed data center, and their effects were verified by numerical simulation. The methods include closing the empty slots of the racks, controlling the opening of the valves under the perforated tiles, and installing an air guide sleeve.

(3) The effects of these methods were calculated and analyzed by evaluation index. It was found that SHI decreases from 0.00051 to 0.00004 , while RHI increases from 0.918 to 0.93 and RTI increases from 0.222 to 0.342 after optimization. The results show that the problem of by-pass of cold air is solved partly.

Also, the methods can also be used in other cases to provide safety and efficient work condition for IT server. The first two methods can be easily implemented for maintainer or owner, and the last one need the cooperation of air conditioning manufacturers or installation contractor.

\section{Acknowledgement}

This work is supported by the National Natural Science Foundation of China (51608405) and the National Key Research and Development Program of China (2018YFC0704301, 2018YFD1100700). 


\section{References}

[1] K. Kant, Data center evolution a tutorial on state of the art, issues, and challenges, Computer Networks. 53 (2009) 2939-2965.

[2] X. Zhou, H. Liu, R. Urata, S. Zebian, Scaling large data center interconnects: challenges and solutions, Optical Fiber Technology. 44 (2018) 61-68.

[3] H. Rong, H. Zhang, S. Xiao, C. Li, C. Hu, Optimizing energy consumption for data centers, Renewable and Sustainable Energy Reviews. 58 (2016) 674-691.

[4] TC 9.9, Mission Critical Facilities, Technology Spaces, and Electronic Equipment, Thermal guidelines for data processing environments, American Society of Heating, Refrigerating and Air-Conditioning Engineers Inc., 2004.

[5] A. Beitelmal, C. Patel, Thermo-fluids provisioning of a high performance high density data center, Distributed and Parallel Databases. 21 (2007) 227-238.

[6] J. Guitart, Toward sustainable data centers: a comprehensive energy management strategy, Computing. 99 (2017) 597-615.

[7] J. Cho, T. Lim, B. Kim, Measurements and predictions of the air distribution systems in high compute density (Internet) data centers, Energy and Buildings. 41 (2009) 1107-1115.

[8] YY. Lui, Waterside and airside economizers design considerations for data center facilities. ASHRAE Trans 116 (2010) 98-108.

[9] JQ Wang, Q. Zhang, Reliability and availability analysis of a hybrid cooling system with water-side economizer in data center, Building and Environment. 148 (2019) 405-416.

[10] H. Zhang, S. Shao , H. Xu, Numerical investigation on integrated system of mechanical refrigeration and thermosyphon for free cooling of data centers. International Journal of Refrigeration, 2015.

[11] J. Cho, J. Yang, W. Park, Evaluation of air distribution system's airflow performance for cooling energy savings in high-density data centers, Energy and Buildings. 68 (2014) 270-279.

[12] S. Nada, K. Elfeky, A. Attia, W. Alshaer, Experimental parametric study of servers cooling management in data centers buildings, Heat and Mass Transfer. 53 (2017) 2083-2097.

[13] P. Kumar , Y. Joshi, Experimental investigations on the effect of perforated tile air jet velocity on server air distribution in a high density data center[C]// Thermal \& Thermomechanical Phenomena in Electronic Systems. 2010.

[14] U.Singh, A. Singh, S. Parvez, A. Sivasubramaniam, CFD-Based Operational Thermal Efficiency Improvement of a Production Data Center. Sustain IT 10, San Jose, California, USA; 2010.

[15] B. Fakhim, M. Behnia, SW. Armfield, Cooling solutions in an operational data centre: A case study[J]. Applied Thermal Engineering. 31(2011)2279-2291.

[16] K Ebrahimi, G F Jones, A S Fleischer, A review of data center cooling technology, operating conditions and the corresponding low-grade waste heat recovery opportunities. Renewable and Sustainable Energy Reviews, 31.2 (2014) 622-638.

[17] CD Patel, A vision of energy aware computing from chips to data centers. In:Proceedings of ISMME 2003. Tsuchiura, Japan; Dec 1-3, 2003.

[18] CE Bash, CD Patel, RK Sharma, Efficient thermal management of data centers- immediate and long-term research needs. HVAC\&R Res 9.2 (2003) 137-52 
[19] RR Schmidt, EE Cruz, MK Iyengar, Challenges of data center thermal management. IBM J Res Dev 49.4/5 (2005) 709-23.

[20] MM Ohadi, SV Dessiatoun, K Choo, M Pecht, JV Lawler, A comparison analysis of air, liquid, and two-phase cooling of data centers. In: Proceedings of the28th IEEE SEMI-THERM symposium. San Jose (CA, USA); March 18-22 (2012) 58-63.

[21] J Rambo, Y Joshi, Modeling of data center airflow and heat transfer: state of the art and future trends. Distrib Parallel Database 21 (2007) 193-225.

[22] K Kant, Data center evolution-A tutorial on state of the art, issues, and challenges. Comput Netw 53 (2009) 2939-65.

[23] E Samadiani, H Amur, B Krishnan, Y Joshi, K Schwan, Coordinated optimization of cooling and IT power in data centers. J Electron Packag 132.031006 (2010) 1-14.

[24] E Samadiani, Y Samadiani, F Mistree, The thermal design of a next generation data center: a conceptual exposition. J Electron Packag 130.041104, (2008) 1-8.

[25] I. Wang, Y. Tsui, C. Wang, Improvements of airflow distribution in a container data center, Energy Procedia. 75 (2015) 1819-1824.

[26] T. Tsuchiya, Y. Suwa, R. Ooka, Experimental study of airflow designs for data centers, Journal of Asian Architecture \& Building Engineering. 13 (2014) 491-498.

[27] Z. Huang, K. Dong, Q. Sun, L. Su, T. Liu, Numerical simulation and comparative analysis of different airflow distributions in data centers, Procedia Engineering. 205 (2017) 2378-2385.

[28] S. Ham, J. Park, J. Jeong, Optimum supply air temperature ranges of various air-side economizers in a modular data center, Applied Thermal Engineering. 77 (2015) 163-179.

[29] E. Oró, A. Garcia, J. Salom, Experimental and numerical analysis of the air management in a datacentre in Spain, Energy and Buildings.116 (2016) 553-561.

[30] S. Nada, M. Said, Effect of CARA units layout on thermal management of data center, Applied Thermal Engineering. 118 (2017) 339-334.

[31] S. Nada, K. Elfeky, Experimental investigations of thermal managements solutions in data centers buildings for different arrangements of cold aisles containments, Building Engineering. 5 (2016) 41-49.

[32] X. Yuan, Y. Wang, J. Liu, X. Xu, X. Yuan, Experimental and numerical study of airflow distribution optimisation in high-density data centre with flexible baffles, Building and Environment. 140 (2018) 128-139.

[33] M. Zhang, Q. An, Z. Long, W. Pan, H. Zhang, X. Cheng, Optimization of airflow organization for a small-scale date center based on the cold aisle closure, Procedia Engineering. 205 (2017) 1893-1900.

[34] C. Gao, Z. Yu, J. Wu, Investigation of airflow pattern of a typical data center by CFD simulation, Energy Procedia. 78 (2015) 2687-2693.

[35] K. Karki, S. Patankar, Airflow distribution through perforated tiles in raised-floor data centers, Building and Environment. 41 (2006) 734-744.

[36] S. Bhopte, D. Agonafer, R. Schmidt, B. Sammakia, Optimization of data center room layout to minimize rack inlet air temperature, Electronic Packaging.128 (2006) 380-387.

[37] K. Karki, A. Radmehr, S. Patankar, Use of computational fluid dynamics for calculating flow rates through perforated tiles in raised-floor data centers, International Journal of Heating, Ventilation, Air-Conditioning, and Refrigeration Research. 9 (2003) 153-166.

[38] M. Zhang, Z. Zhang, Y. Yu, Y. Geng, H. Huang, Y. Huang, Effect of raised floor height on 
different arrangement of under-floor air distribution performance in data center, Procedia Engineering. 205 (2017) 556-564.

[39] M. Zhang, Z. Zhang, Y. Yu, Y. Geng, H. Huang, Y. Huang, Effect of raised floor height on different arrangement of under-floor air distribution performance in data center, Procedia Engineering. 205 (2017) 556-564.

[40] A. Bhalerao, K. Fouladi, Rapid prediction of exergy destruction in data centers due to airflow mixing, Numerical Heat Transfer. 70 (2016) 48-63.

[41] R. Sharma, C. Bash, C. Patel, Dimensionless parameters for evaluation of thermal design and performance of large-scale data centers, AIAA/ASME Joint Thermophysics and Heat Transfer Conference. 2002

[42] C. Bash, C. Patel, R. Sharma, Efficient thermal management of data centers-immediate and long-term research needs, HVAC \& R Research. 9 (2003)137-152.

[43] M. Herrlin, Rack Cooling effectiveness in data centers and telecom central offices: the rack cooling index (RCI), Ashrae Transactios. 111 (2005)725-731.

[44] K Fouladi, A P Wemhoff, L Silva-Llanca, Optimization of data center cooling efficiency using reduced order flow modeling within a flow network modeling approach. Applied Thermal Engineering, (2017) V08BT10A082-V08BT10A082.

[45] XL Yuan, XT Zhou, JX Liu, Experimental and numerical investigation of an airflow management system in data center with lower-side terminal baffles for servers. Building and Environment. 155 (2019) 308-319.

[46] A R I Mukaffi, R S Arief, W Hendradjit, Optimization of Cooling System for Data Center Case Study: PAU ITB Data Center. Procedia Engineering, 170 (2017):552-557.

[47] T. Chen, X. Wang, G B Giannakis, Cooling-Aware Energy and Workload Management in Data Centers via Stochastic Optimization. IEEE Journal of Selected Topics in Signal Processing, 10.2 (2016) 402-415.

[48] C. Nadjahi, H. Louahlia-Gualous, Experimental study and analytical modeling of thermosyphon loop for cooling data center racks, Heat and Mass Transfer. 56(2020)121-142.

[49] XL Yuan, XT Zhou, JX Liu, Experimental and numerical investigation of an airflow management system in data center with lower-side terminal baffles for servers. Building and Environment. 155 (2019) 308-319.

[50] CQ Jin, XL Bai, YN An, X Zhan, Comparative analysis of thermal environment between raised-floor and row-based cooling in a campus data center. IOP Conference Series: Materials Science and Engineering. 609(2019)32-58.

[51] S. Nada, M. Said, M. Rady, Numerical investigation and parametric study for thermal and energy management enhancements in data centers' buildings, Applied Thermal Engineering. 98 (2016) 110-128. 
The first author: Xiongzhuang Meng(1997-), Male, Master degree candidate,Address:430070,School of Civil Engineering and Architecture, Wuhan University of Technology, Wuhan, Hubei,E-mail: 194889188@ whut.edu.cn

Corresponding author: Junli Zhou(1977-), Female, Associate professor, Address: 430070, School of Civil Engineering and Architecture, Wuhan University of Technology, Wuhan, Hubei, E-mail : jlzhou @ whut.edu.cn 
Table.1. IT equipment thermal environmental specifications

\begin{tabular}{|c|c|c|c|c|c|}
\hline \multirow{2}{*}{ Class } & \multicolumn{2}{|c|}{ Allowable } & \multicolumn{2}{|c|}{ Recommended } & \multirow{2}{*}{$\begin{array}{c}\text { Dew-point } \\
\left({ }^{\circ} \mathrm{C}\right)\end{array}$} \\
\hline & $\mathrm{DB}\left({ }^{\circ} \mathrm{C}\right)$ & $\mathrm{RH}(\%)$ & $\mathrm{DB}\left({ }^{\circ} \mathrm{C}\right)$ & $\mathrm{RH}(\%)$ & \\
\hline 1 & $15-32$ & $20-80$ & $20-25$ & $40-55$ & 17 \\
\hline 2 & $15-35$ & $20-80$ & $20-25$ & $40-55$ & 21 \\
\hline 3 & $5-35$ & $8-80$ & N/A & N/A & 28 \\
\hline 4 & $5-40$ & $8-80$ & N/A & N/A & 28 \\
\hline NEBS & $5-40$ & $5-85$ & $18-27$ & $\operatorname{Max} 55$ & 28 \\
\hline
\end{tabular}

*DB, RH and NEBS represents the dry ball temperature, relative humidity and network equipment-building system respectively.

Table 2. Summary of typical air-cooled data center heat sources and streams[13].

\begin{tabular}{ll}
\hline Parameter & Value \\
\hline Cold aisle (CRAC supply) temp. & $10-32{ }^{\circ} \mathrm{C}$ \\
Hot aisle (CRAC return) temp. & $50-60{ }^{\circ} \mathrm{C}$ \\
Temp. rise over server & $10-20{ }^{\circ} \mathrm{C}$ \\
Airflow per rack & $200-2500 \mathrm{CFM}$ \\
Chiller water supply to CRAC & $7-10{ }^{\circ} \mathrm{C}$ \\
Chilled water return from CRAC & $35^{\circ} \mathrm{C}$ \\
\hline
\end{tabular}

*CFM represents the cubic feet per minute

Table 3. Thermal environment evaluation index

\begin{tabular}{|c|c|c|c|c|c|}
\hline Index & SHI & RHI & $\beta$ & RCI & RTI \\
\hline Definition & $\frac{\delta Q}{Q+\delta Q}$ & $\frac{Q}{Q+\delta \mathrm{Q}}$ & $\frac{T_{i n}-T_{r e f}}{T_{\text {out }}-T_{\text {in }}}$ & $\begin{array}{l}\mathrm{RCI}_{\mathrm{HI}} \\
\mathrm{RCI}_{\mathrm{LO}}\end{array}$ & $\frac{T_{\text {return }}-T_{\text {supply }}}{\Delta T_{\text {equipment }}}$ \\
\hline Explain & $\begin{array}{l}\text { More close to } 0, \\
\text { the smaller } \\
\text { deviations } \\
\text { between the } \\
\text { average inlet } \\
\text { temperature of } \\
\text { the rack and the } \\
\text { air supply } \\
\text { temperature of } \\
\text { the air } \\
\text { conditioner. }\end{array}$ & $\begin{array}{l}\text { More close to } 1 \text {, } \\
\text { the less mixing } \\
\text { of hot and cold } \\
\text { air will occur. }\end{array}$ & $\begin{array}{l}\text { The smaller the } \\
\text { value is, the } \\
\text { better the airflow } \\
\text { organization } \\
\text { evaluation will } \\
\text { be. If > 1, it } \\
\text { indicates that the } \\
\text { airflow } \\
\text { self-circulation } \\
\text { occurs in the } \\
\text { rack. }\end{array}$ & $\begin{array}{l}\text { The optimal } \\
\text { value is } 1 \text {, and } \\
\text { the difference } \\
\text { from } 1 \text { indicates } \\
\text { that the deviation } \\
\text { from the } \\
\text { standard of the } \\
\text { overall wind } \\
\text { inlet condition. }\end{array}$ & $\begin{array}{l}\text { If }>1 \text {, the rack is } \\
\text { dominated by hot } \\
\text { air re-circulation; } \\
\text { otherwise, the } \\
\text { cold air by-pass } \\
\text { is mainly used, } \\
\text { and the deviation } \\
\text { from } 1 \text { will lead } \\
\text { to poor airflow } \\
\text { organization. }\end{array}$ \\
\hline
\end{tabular}


Table 4. Summary of instruments

\begin{tabular}{cccc}
\hline Name & Type & Range & Accuracy \\
\hline Wind speed and temperature & WFWZY-1 & $-20-80{ }^{\circ} \mathrm{C}$ & $\pm 0.01^{\circ} \mathrm{C}$ \\
recorder & & $0.05-30 \mathrm{~m} / \mathrm{s}$ & $\pm 0.01 \mathrm{~m} / \mathrm{s}$ \\
Thermal imager & Flir-B425 & $-20-120^{\circ} \mathrm{C}$ & $\pm 0.1^{\circ} \mathrm{C}$ \\
\hline
\end{tabular}

Table 5. Layout of measuring points

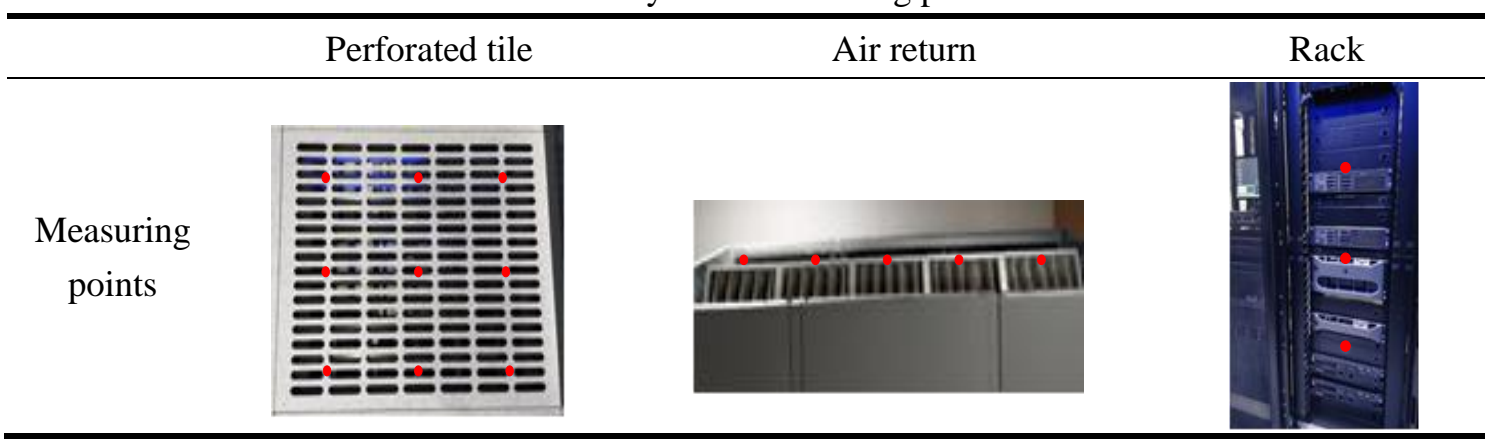

Table 6. Infrared thermography images of the computer room

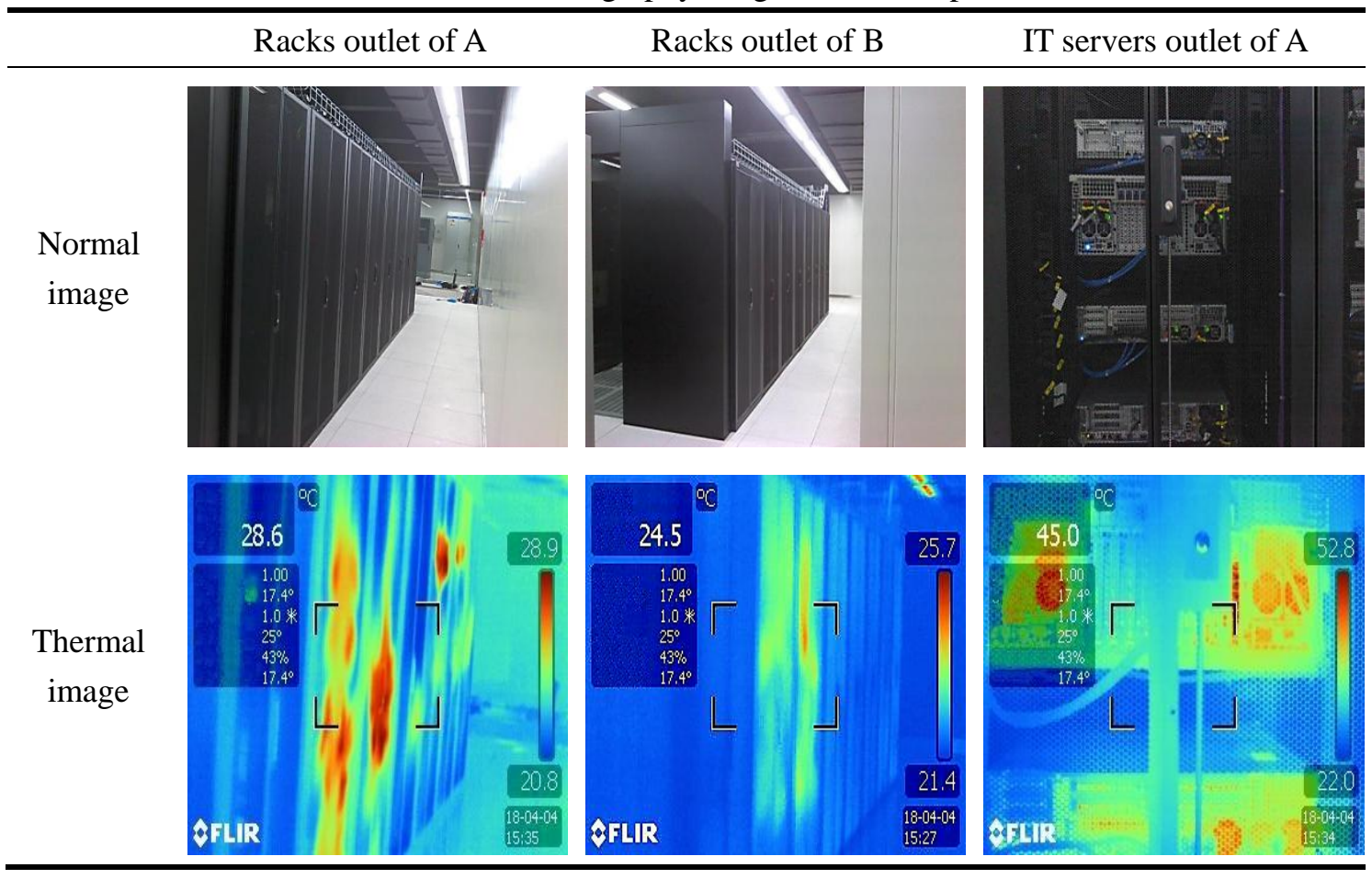

Table 7.The type A standard uncertainty of the outlet of No.6 rack

\begin{tabular}{ccc}
\hline Area & Wind Speed $(\mathrm{m} / \mathrm{s})$ & Temperature $\left({ }^{\circ} \mathrm{C}\right)$ \\
\hline Upper part & 0.095 & 0.336 \\
Middle part & 0.082 & 0.310 \\
Under part & 0.105 & 0.335 \\
\hline
\end{tabular}


Table 8. The combined standard uncertainty of the outlet of No.6 rack

\begin{tabular}{rcc}
\hline & Wind speed $(\mathrm{m} / \mathrm{s})$ & Temperature $\left({ }^{\circ} \mathrm{C}\right)$ \\
\hline Upper part & 0.096 & 0.336 \\
Middle part & 0.083 & 0.310 \\
Under part & 0.105 & 0.335 \\
\hline
\end{tabular}


Table 9. Comparison of measured and simulated values

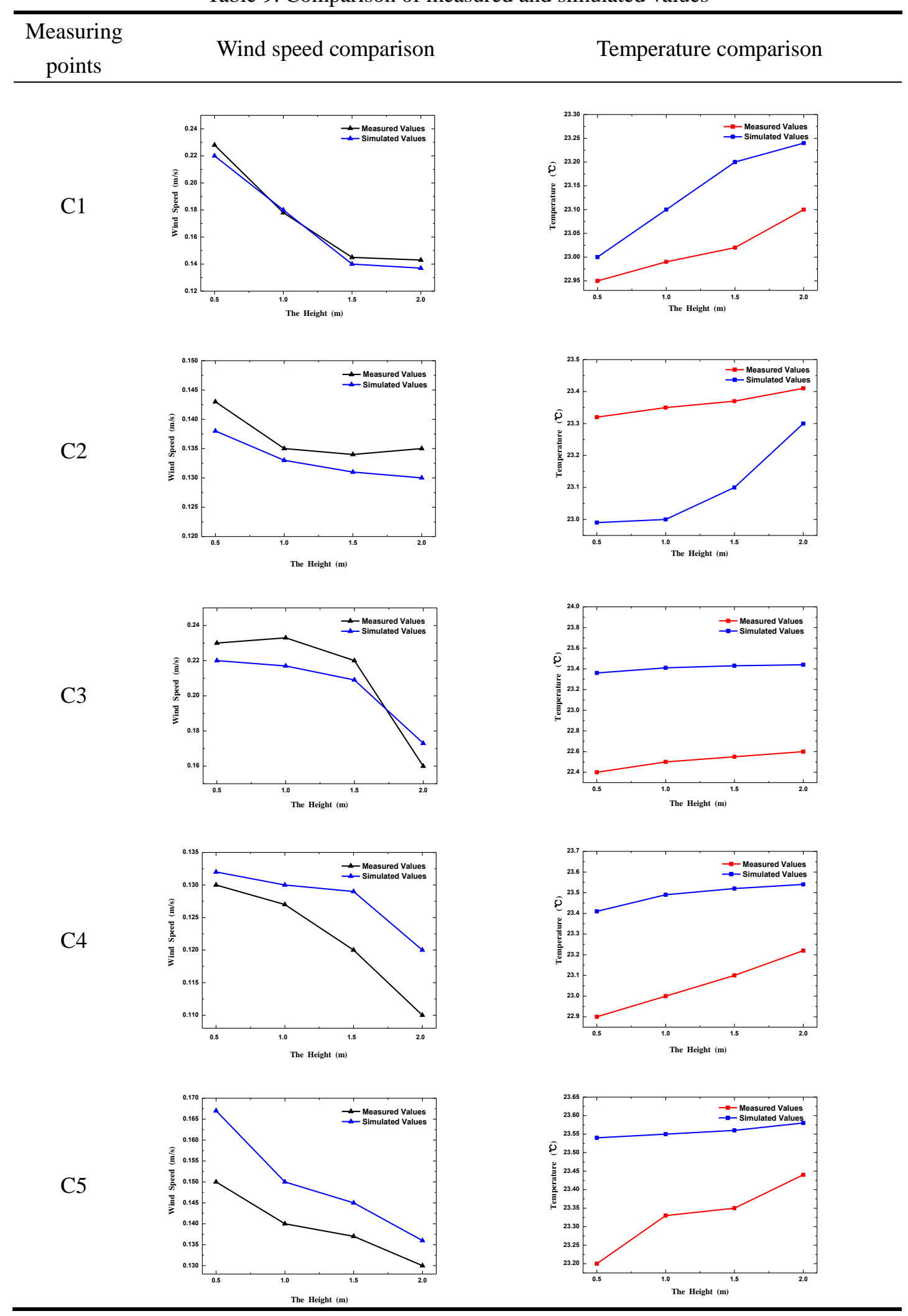


Table 10. Temperature distribution of racks

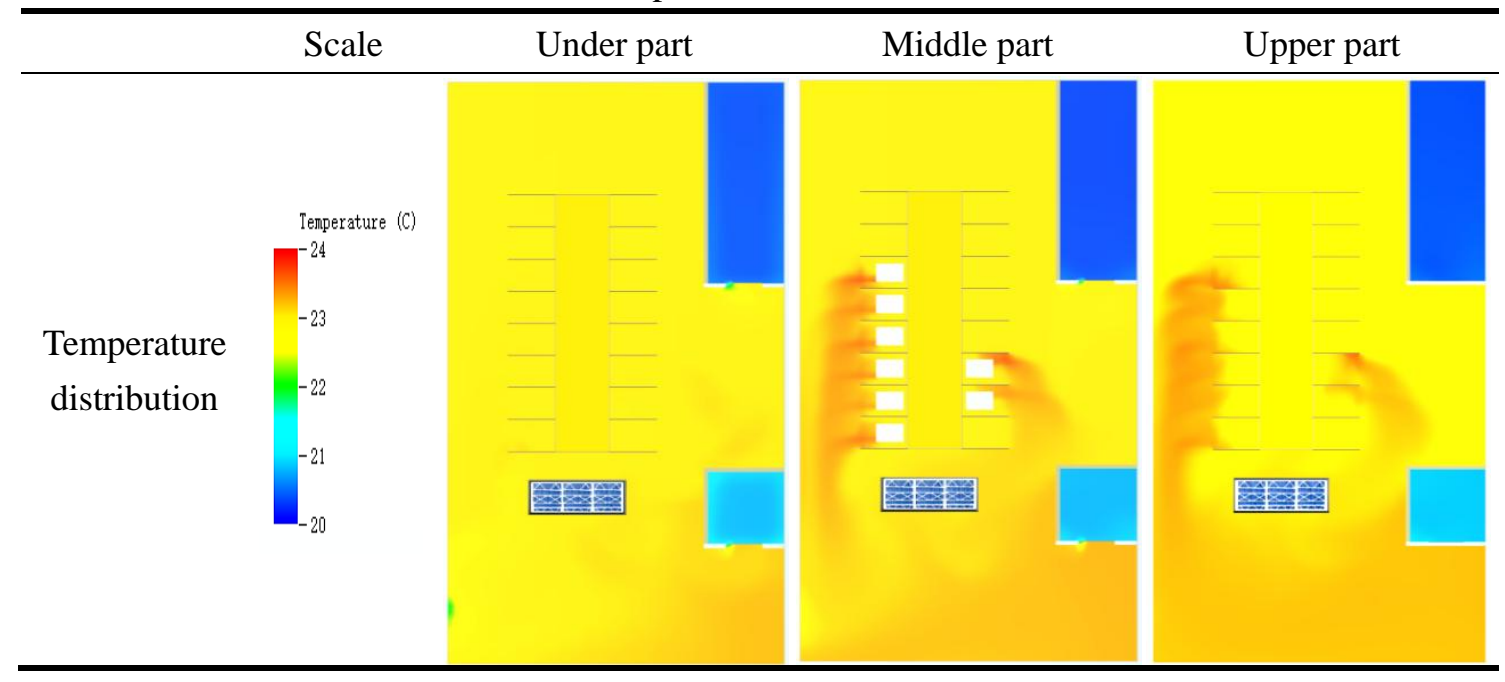

Table 11. Streamline distribution

\begin{tabular}{llll|}
\hline & Air flow in the cold aisle & Air flow around air conditioner \\
\hline $\begin{array}{l}\text { Streamline } \\
\text { distribution }\end{array}$ & &
\end{tabular}


Table 12. Comparison of results before and after optimization

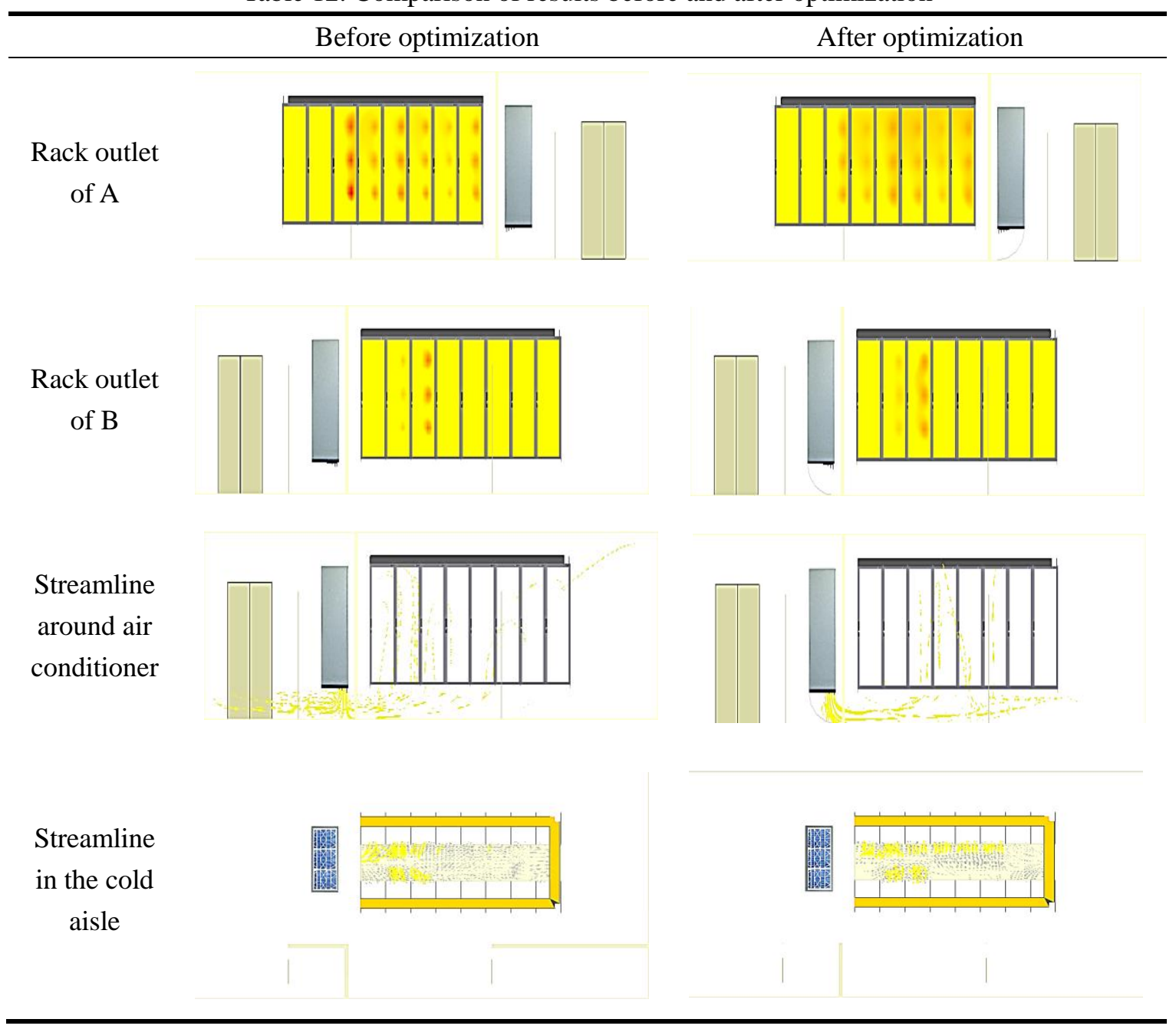

Table 13. Thermal environment evaluation index of the computer room

\begin{tabular}{ccccc}
\hline Index & SHI & RHI & RCI & RTI \\
\hline $\begin{array}{c}\text { Before } \\
\text { optimization design }\end{array}$ & 0.00051 & 0.918 & 1 & 0.222 \\
$\begin{array}{c}\text { After } \\
\text { optimization design }\end{array}$ & 0.00004 & 0.93 & 1 & 0.342 \\
\hline
\end{tabular}




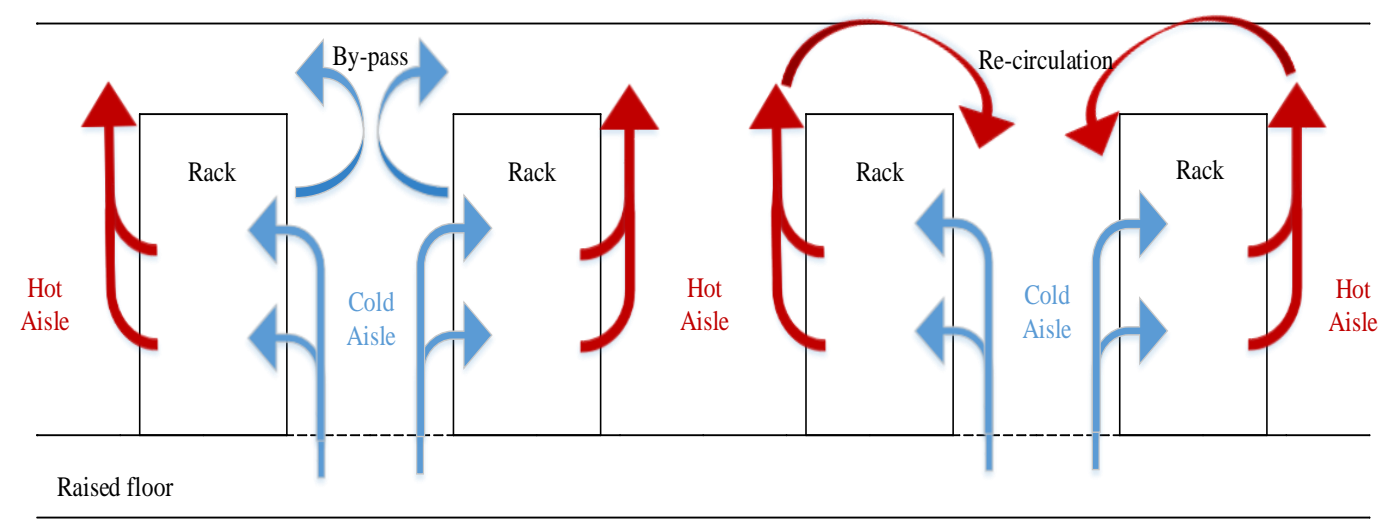

Fig. 1. Actual airflow in a computer room

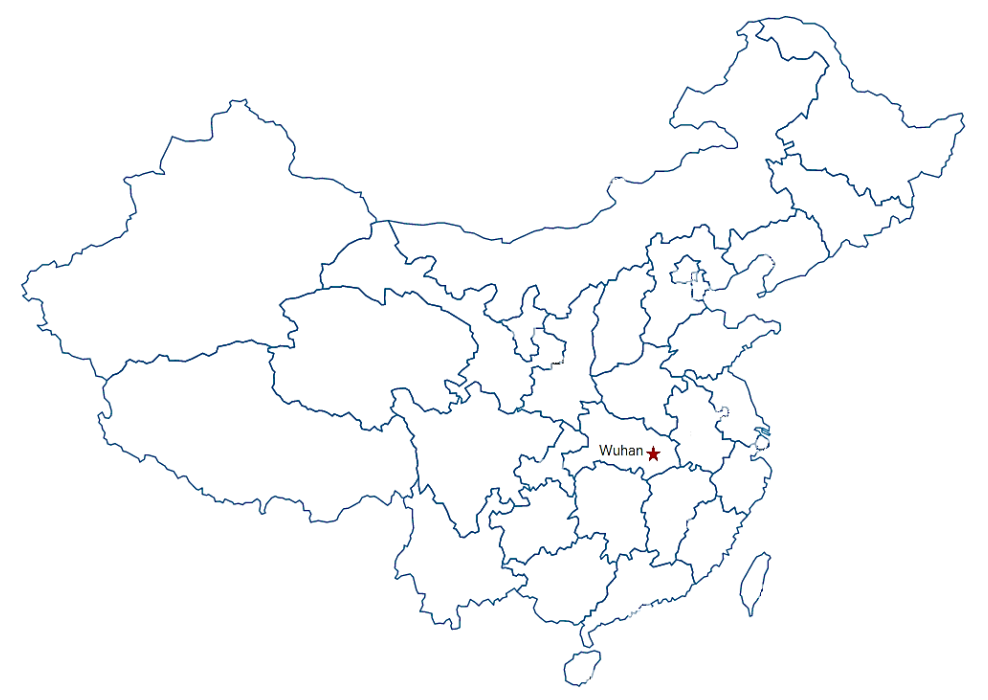

Fig. 2. Map of Wuhan's geographical location in China 


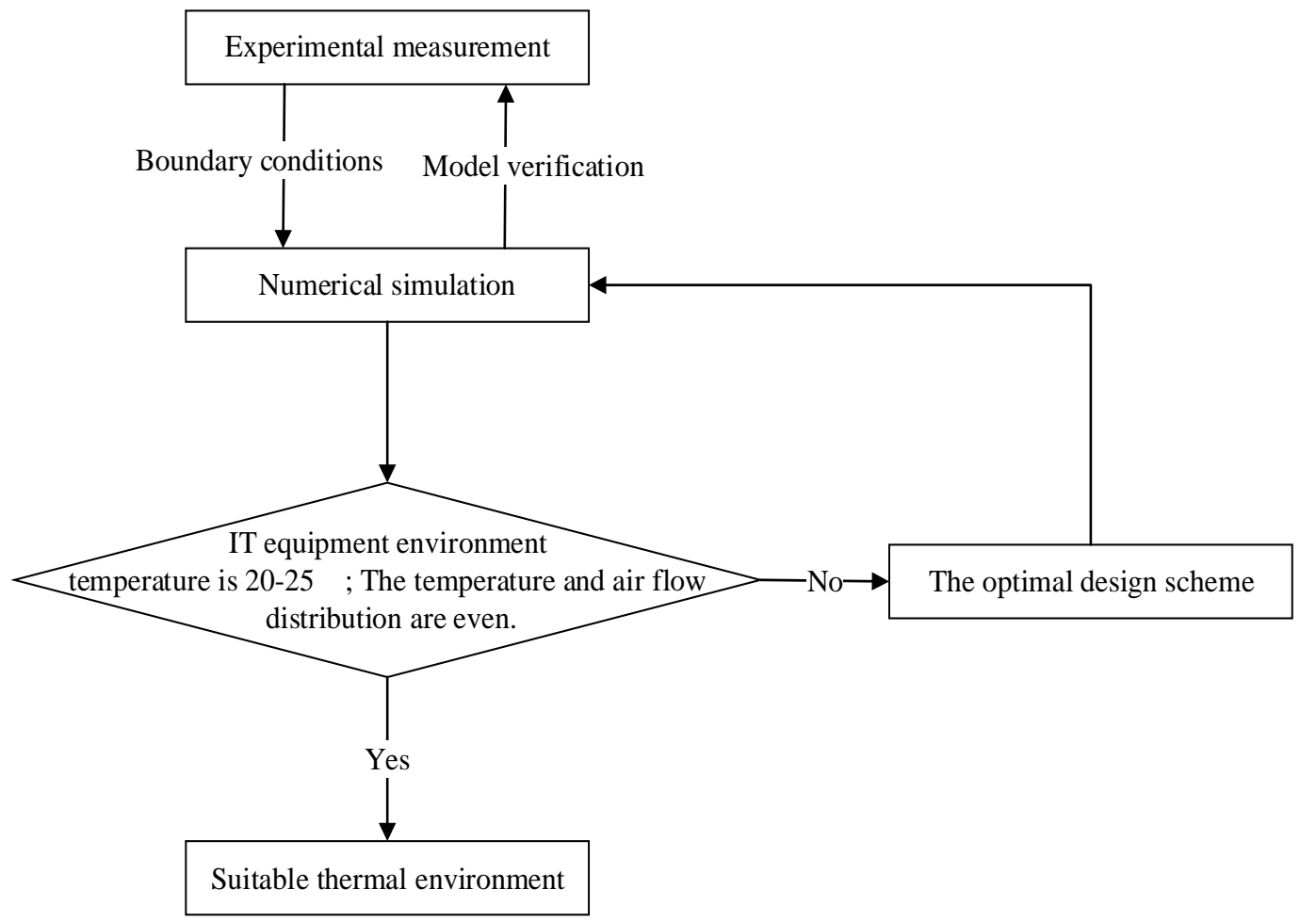

Fig. 3. Research procedure

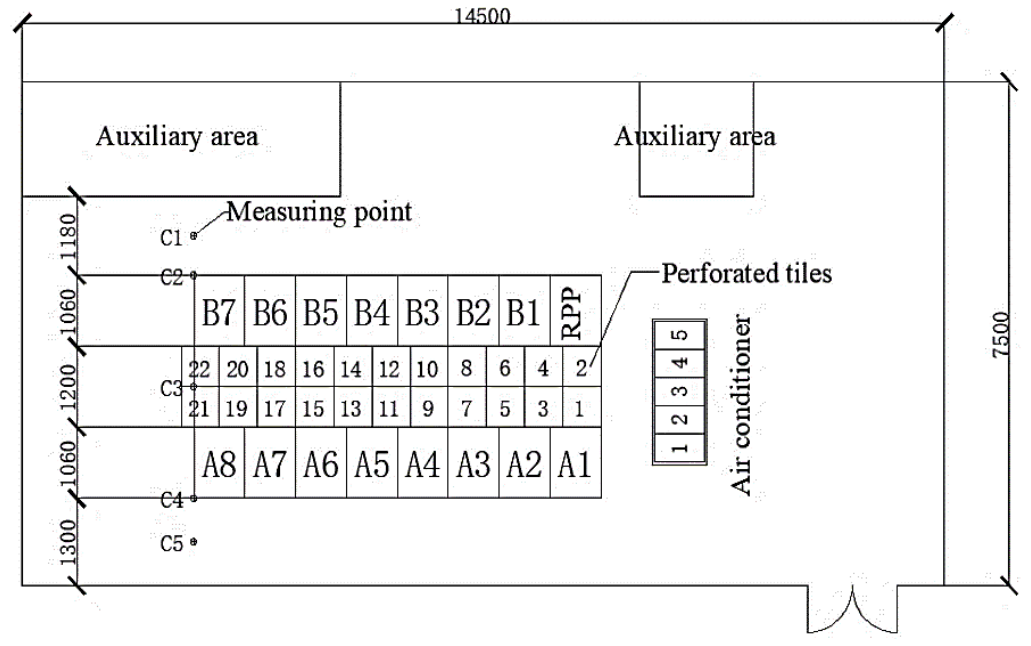

Fig. 4. Rack number and layout of the computer room 


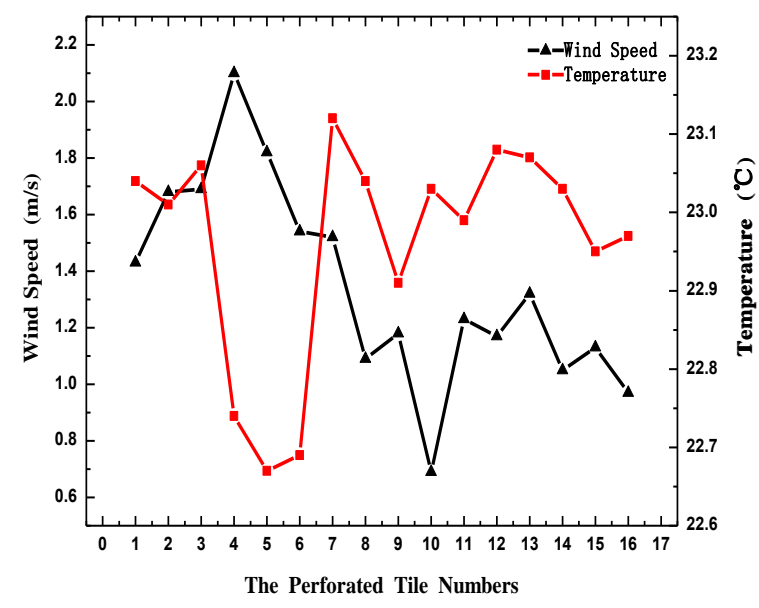

(a) The results of perforated tile

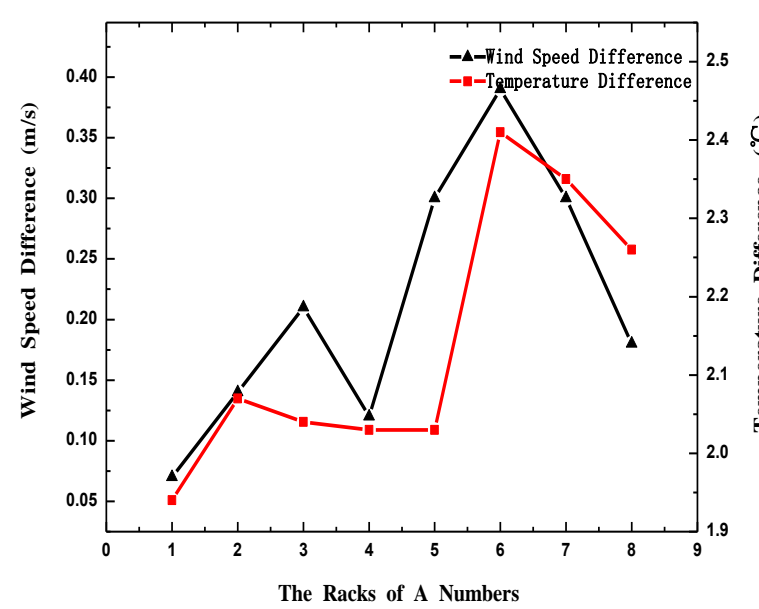

(c) The results of racks of $\mathrm{A}$

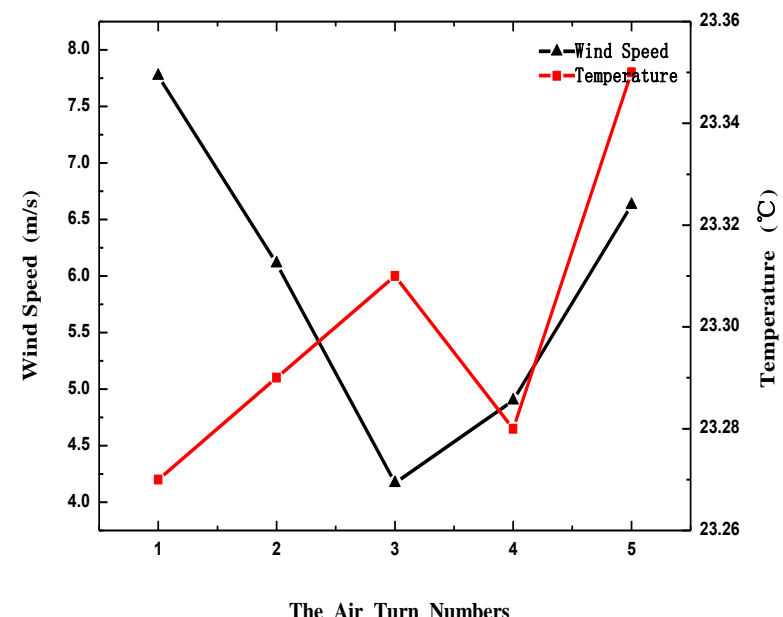

(b) The results of air turn

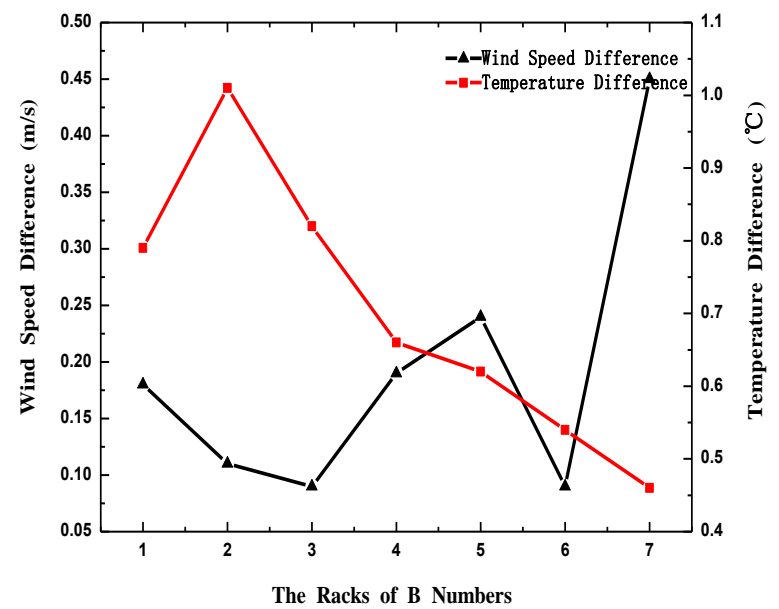

(d) The results of racks of B

Fig. 5. Wind speed and temperature of field experiment 


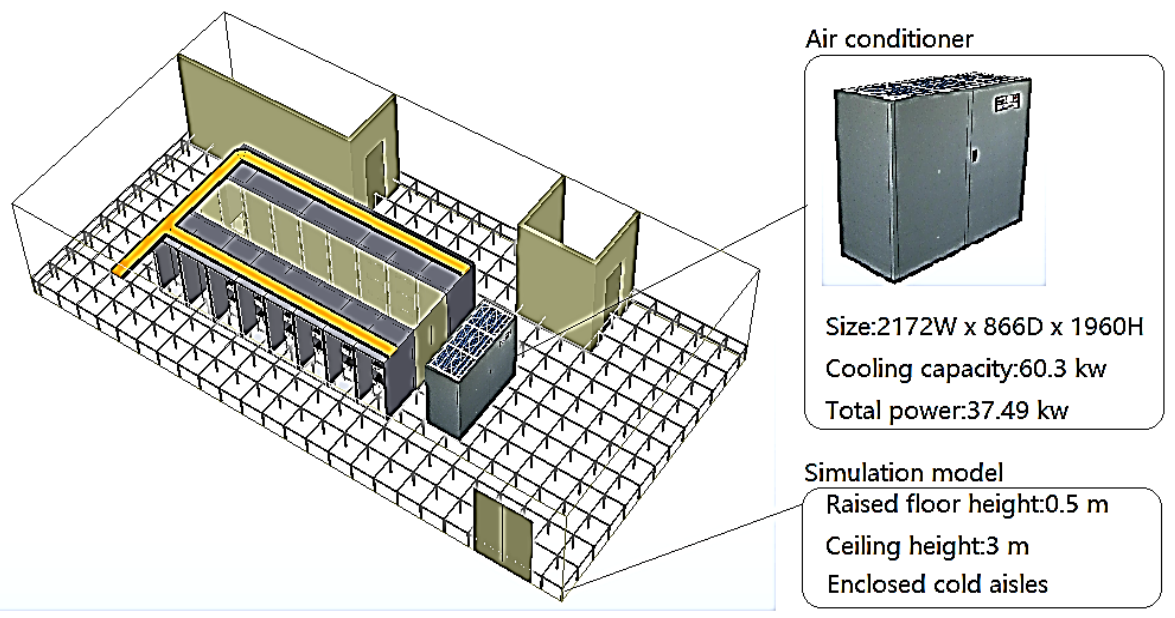

Fig. 6. Computer room model

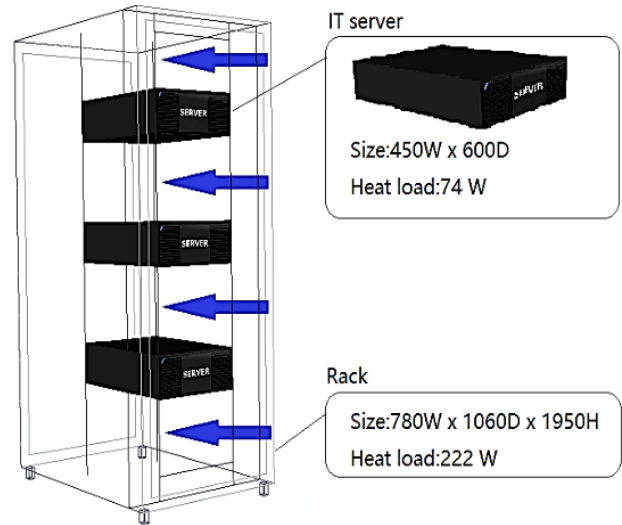

Fig. 7. Rack model

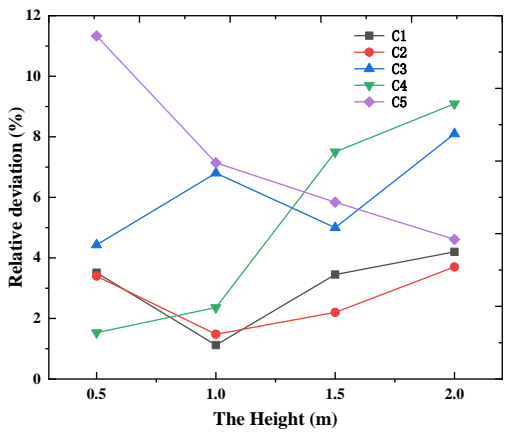

(a) Relative deviation of wind speed

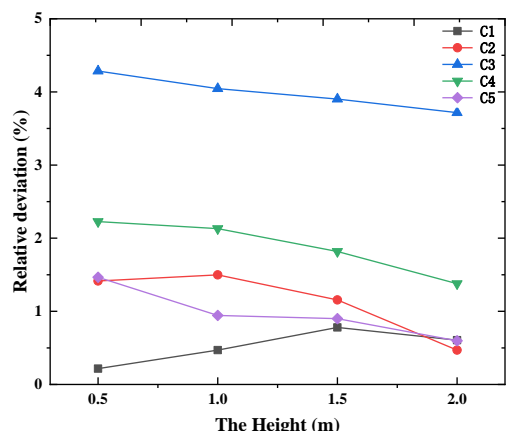

(b) Relative deviation of temperature

Fig. 8. Relative deviation of 5 points between the experimental and numerical results 


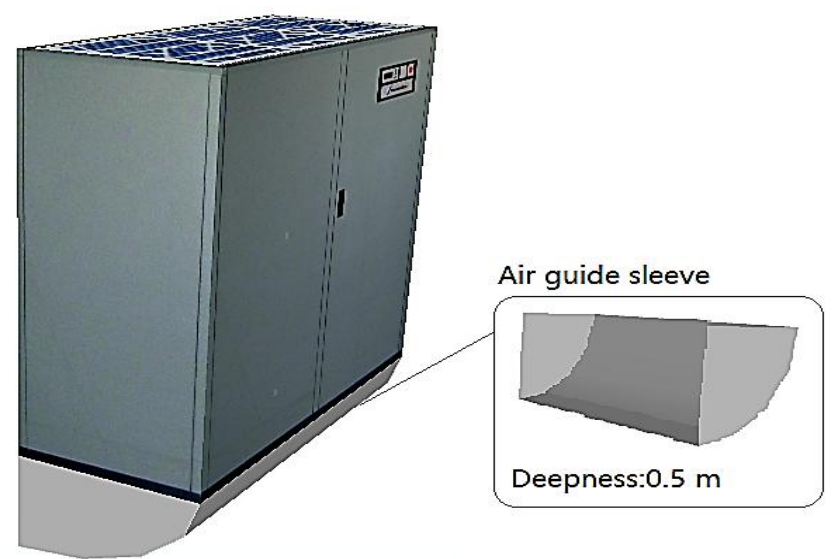

Fig. 9. Installation diagram of air guide sleeve 